\title{
Cysteine Mutants of the Major Facilitator Superfamily-Type Transporter CcoA Provide Insight into Copper Import
}

\author{
Bahia Khalfaoui-Hassani ${ }^{a, b}$, Petru-Iulian Trasnea ${ }^{a,{ }^{*}}$, Stefan Steimle ${ }^{a}$, Hans-Georg \\ Koch $^{\mathrm{c}}$, and Fevzi Daldala
}

a Department of Biology, University of Pennsylvaniagrid.25879.31, Philadelphia, Pennsylvania, USA

bUniversité de Pau et des Pays de l'Adour, E2S UPPA, IPREM, UMR CNRS 5254, Pau, France

${ }^{C}$ Institute of Biochemistry and Molecular Biology, ZBMZ, Faculty of Medicine, Albert Ludwigs University of Freiburg, Freiburg, Germany

ABSTRACT CCOA belongs to the widely distributed bacterial copper $(\mathrm{Cu})$ importer subfamily CalT (드스-like Iransporters) of the Major Facilitator Superfamily (MFS) and provides cytoplasmic $\mathrm{Cu}$ needed for $c b b_{3}$-type cytochrome $c$ oxidase ( $c b b_{3}$-Cox) biogenesis. Earlier studies have supported a 12-transmembrane helix (TMH) topology

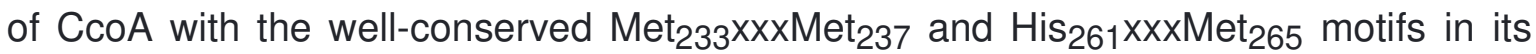

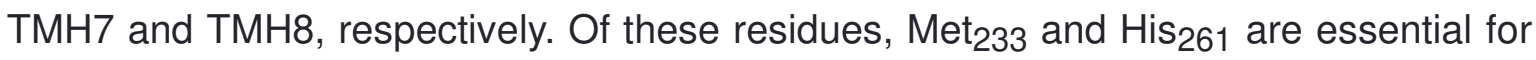
$\mathrm{Cu}$ uptake and $\mathrm{cb}_{3}-\mathrm{Cox}$ production, whereas $\mathrm{Met}_{237}$ and $\mathrm{Met}_{265}$ contribute partly to these processes. CcoA also contains five Cys residues of unknown role and, remarkably, its structural models predict that three of these are exposed to the highly oxidizing periplasm. Here, we first demonstrate that elimination of both $\mathrm{Met}_{237}$ and Met 265 completely abolishes $\mathrm{Cu}$ uptake and $\mathrm{cbb}_{3}$-Cox production, indicating that CcoA requires at least one of these two Met residues for activity. Second, using scanning mutagenesis to probe plausible metal-interacting Met, His, and Cys residues of CcoA, we found that the periplasm-exposed $\mathrm{Cys}_{49}$ located at the end of $\mathrm{TMH}_{2}$, the $\mathrm{Cys}_{247}$ on a surface loop between TMH7 and THM8, and the $\mathrm{C}_{367}$ located at the end of TMH11 are important for CcoA function. Analyses of the single and double Cys mutants revealed the occurrence of a disulfide bond in $\mathrm{CcoA}$ in vivo, possibly related to conformational changes it undergoes during $\mathrm{Cu}$ import as MFS-type transporter. Our overall findings suggest a model linking $\mathrm{Cu}$ import for $c b b_{3}-\mathrm{Cox}$ biogenesis with a thiol:disulfide oxidoreduction step, advancing our understanding of the mechanisms of CcoA function.

IMPORTANCE Copper $(\mathrm{Cu})$ is a redox-active micronutrient that is both essential and toxic. Its cellular homeostasis is critical for supporting cuproprotein maturation while avoiding excessive oxidative stress. The $\mathrm{Cu}$ importer $\mathrm{CcoA}$ is the prototype of the widespread CalT subfamily of the MFS-type transporters. Hence, understanding its molecular mechanism of function is significant. Here, we show that CcoA undergoes a thiol:disulfide oxidoreduction cycle, which is important for its $\mathrm{Cu}$ import activity.

KEYWORDS copper uptake, $c b b_{3}$-type cytochrome $c$ oxidase, copper-binding residues, MFS-type transporters, Rhodobacter capsulatus CcoA, bacterial copper import, copper binding residues, Rhodobacter capsulatus, bacterial copper 
Received 27 May 2021 Accepted 9 June 2021 Published 20 July 2021

* Present address: Petru-Iulian Trasnea, Institute of Science and Technology, Klosterneuburg, Austria.

Citation Khalfaoui-Hassani B, Trasnea P-I, Steimle S, Koch H-G, Daldal F. 2021. Cysteine mutants of the major facilitator superfamily-type transporter CcoA provide insight into copper import. mBio 12:e01567-21. https://doi.org/10.1128/mBio.01567-21.

Editor Gisela Storz, National Institute of Child Health and Human Development

Copyright (C) 2021 Khalfaoui-Hassani et al. This is an open-access article distributed under the terms of the Creative Commons Attribution 4.0 International license.

\section{T} he major facilitator superfamily (MFS) is one of the largest groups of secondary active transporters that are exceptionally diverse and ubiquitous to all three kingdoms of life. MFS members selectively transport a wide range of substrates, including sugars, amino acids, peptides, and antibiotics, either by utilizing the electrochemical gradient due to differential substrate concentration or by coupling the transport of one substrate to that of another via the so-called alternating-access mechanism $(1,2)$.

A typical MFS protein comprises 400 to 600 amino acids often arranged as 12 transmembrane $\alpha$-helices (TMHs) in two pseudosymmetrical six $\mathrm{N}$-terminal ( $\mathrm{N}$-ter) and six C-terminal (C-ter) TMH bundles, with both termini on the inner $(n)$ side of the cytoplasmic membrane. In most cases, MFS proteins contain a substratebinding cavity enclosed by the $\mathrm{N}$ - and $\mathrm{C}$-ter domains and located about halfway into the membrane. The three-dimensional (3D) structures of several MFS transporters are available, and they exhibit different conformational states, supporting an alternating-access cycle mechanism of function (3-5). Accordingly, MFS-type transporters undergo a series of conformational changes to upload, and subsequently to release, their substrates across the membrane. These conformations are referred to as outward-open, outward-facing-occluded, inwardfacing-occluded, and inward-open states. The interactions of the substrate with specific residues during its binding and its release are thought to trigger the dynamics of interdomain interactions $(3,6)$. The nature and location of the residues that selectively bind the substrate and those that trigger the conformational changes required for transport may differ among the MFS proteins. In the case of the lactose permease LacY, the residues TMH4-Glu 126 and TMH5$\mathrm{Arg}_{144}$ are essential for sugar binding, whereas the TMH7-Tyr 236 , TMH8-Glu 269 , and $\mathrm{TMH}_{10} \mathrm{-H} \mathrm{H}_{322}$, which are close to one another in the inward-facing structure, coordinate the closing and the opening of the protein upon substrate binding and release $(7,8)$. For the oligopeptide transporter PepT, the residues $\mathrm{TMH}_{1}-\mathrm{Tyr}_{29}$,

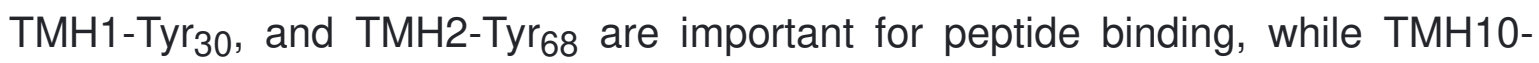
Gly 407 and TMH11-Trp 427 form the pivotal points that control the occluded and the inward-facing conformational states of PepT (9).

The MFS-type transporter $\mathrm{CcoA}$ was the first copper $(\mathrm{Cu})$ importer reported in bacteria (10-12) and has become the prototype of the large CalT ( $\underline{C} c 0 \underline{A}$-like Transporters) subfamily of $\mathrm{Cu}$ transporters (13). It was initially identified in the facultative phototroph Rhodobacter capsulatus, where it is required for the biogenesis of the binuclear heme- $\mathrm{Cu}\left(\mathrm{Cu}_{\mathrm{B}}\right)$ center of $c b b_{3}$-type cytochrome $c$ oxidases ( $c b b_{3}$-Cox) (14), a $\mathrm{C}$ family of heme- $\mathrm{Cu} \mathrm{O}_{2}$ reductase. Comparative phylogenomics of $\mathrm{CcoA}$ orthologs showed that they are widespread among the 
alphaproteobacteria (15). In species like Rhodobacter sphaeroides, which produces multiple heme- $\mathrm{Cu} \mathrm{O}_{2}$ reductases, $\mathrm{CcoA}$ is specific to $c b b_{3}$-Cox and not involved in the maturation of the closely related aaz-type Cox (15). This is noteworthy because both the $c b b_{3}-\mathrm{Cox}$ and $a a_{3}-\mathrm{Cox}$ have similar heme-CuB centers (16). Distant orthologs of $R$. capsulatus $\mathrm{CcoA}$, initially thought to transport riboflavin, were shown to import $\mathrm{Cu}$ (13), and their occurrence in some proteobacteria lacking $\mathrm{Cbb}_{3}$-Cox suggests that $\mathrm{CcoA}$-imported $\mathrm{Cu}$ is likely destined to other cuproproteins in these species. Thus, the CalT family members might have a broader role extending beyond the $c b b_{3}$-Cox biogenesis.

Previous studies addressing the $\mathrm{Cu}$ binding and import functions of $\mathrm{CcoA}$ revealed two motifs, $M_{233} \times x \times M_{237}$ and $H_{261} \times x \times M_{265}$, that are well conserved among its homologs (17). The membrane topology of $\mathrm{CcoA}$ and locations of these motifs in the predicted TMH7 and TMH8 suggested that they are parts of its membrane-buried $\mathrm{Cu}$ binding site (Fig. 1, left panel). Substitution of these residues with alanine, which is unable to ligand metals, and analyses of the ensuing mutants for ${ }^{64} \mathrm{Cu}$ uptake and $\mathrm{cbb}_{3}$-Cox production had shown that the $\mathrm{M}_{233}$ and $\mathrm{H}_{261}$ residues are essential for CcoA activity, whereas substitution of $\mathrm{M}_{237}$, or $M_{265}$, which are also parts of the conserved motifs, only partially affected the function (17). The putative $\mathrm{Cu}$ binding site of CcoA suggested that its mode of action was likely to be different from other well-studied eukaryotic $\mathrm{Cu}$ transporters, such as the Ctr-type (18) or the P-type (19) ATPase proteins.
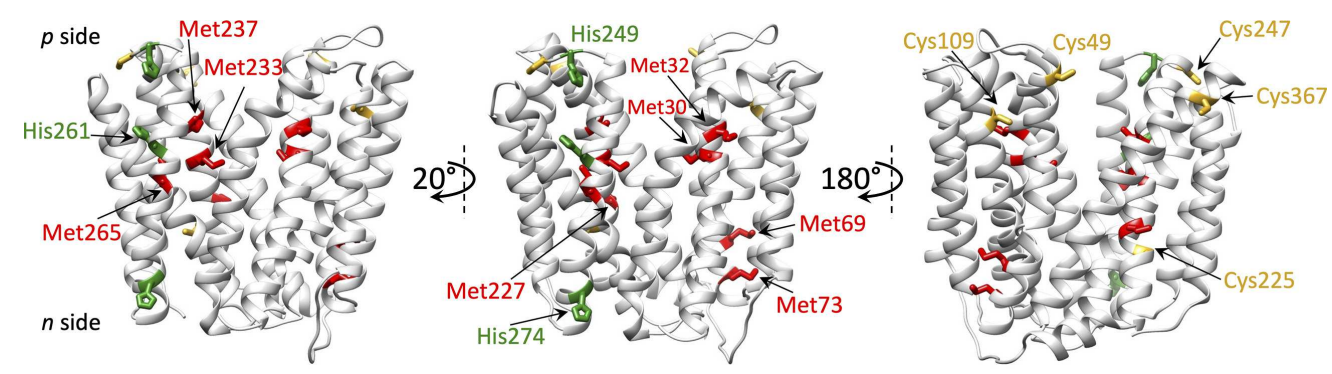

FIG 1 CcoA homology model using YajR as a template ( $\left.\mathrm{CcOA}_{Y a j R}\right)$ and locations of its selected Met, His, and Cys residues. Different views of $\mathrm{CCOA}_{Y a j R}$ model generated using SWISS-MODEL (http://swissmodel.expasy.org; GMQE 0.51) are shown to highlight the respective locations of the conserved motifs $\left(\mathrm{M}_{233} \times \mathrm{xxM}_{237}\right.$ and $\left.\mathrm{H}_{261} \times \mathrm{xxM}_{265}\right)$ proposed to bind $\mathrm{Cu}$ (left), the selected Met $\left(\mathrm{M}_{30}, \mathrm{M}_{32}, \mathrm{M}_{69}, \mathrm{M}_{73}\right.$, and $\left.\mathrm{Met}_{227}\right)$ and $\mathrm{His}\left(\mathrm{H}_{249}\right.$ and $\left.\mathrm{H}_{274}\right)$ (middle), and the Cys $\left(\mathrm{C}_{49}, \mathrm{C}_{109}\right.$, $\mathrm{C}_{225}, \mathrm{C}_{247}$, and $\mathrm{C}_{367}$ ) (right) residues of $\mathrm{CcoA}$ examined in this study. The Met, His, and Cys residues are colored in red, green, and yellow, respectively.

Here, $\mathrm{Cu}$ import by R. capsulatus CcoA was studied in further detail. First, to better define the role of the $M_{237}$ and $M_{265}$ residues, a double mutant, $M_{237} A+M_{265} A$, was obtained and shown to be completely defective for $\mathrm{Cu}$ import and $\mathrm{Cbb}_{3}$-Cox activity, in contrast to the respective single mutants. In addition, the roles of selected five Met $\left(M_{30}, M_{32}, M_{69}, M_{73}\right.$, and $\left.M_{227}\right)$, two $H i s\left(H_{249}\right.$ and $\left.\mathrm{H}_{274}\right)$, and five Cys $\left(\mathrm{C}_{49}, \mathrm{C}_{109}, \mathrm{C}_{225}, \mathrm{C}_{247}\right.$, and $\left.\mathrm{C}_{367}\right)$ residues of $\mathrm{CcoA}$ (Fig. 1, middle and right panels) were examined by monitoring the $c b b_{3}$-Cox activities after mutagenesis. The results support a hypothetical model for $R$. capsulatus CcoA function, possibly involving thiol:disulfide exchange reactions between its periplasm-facing Cys residues during $\mathrm{Cu}$ import.

\section{RESULTS}

Either $\mathbf{M}_{237}$ or $\mathbf{M}_{265}$ residues of $\mathrm{CcoA}$ are required for $\mathrm{Cu}$ import. Earlier studies showed that mutants lacking $\mathrm{CcoA}$ were unable to accumulate ${ }^{64} \mathrm{Cu}$ in a 
CcoA-specific (i.e., temperature-dependent) manner (12). Indeed, mutagenesis of the $M_{233}$ and $H_{261}$ residues of CcoA conserved motifs $\left(M_{233} X X X M_{237}\right.$ and $\mathrm{H}_{261} X X X M_{265}$ ) (Fig. 1, left panel) completely abolished $c b b_{3}$-Cox activity (Table 1), and cellular ${ }^{64} \mathrm{Cu}$ accumulation, while mutating $M_{237}$ or $M_{265}$ only partially decreased these activities (17). The results indicated that the conserved $M_{233}$ and $\mathrm{H}_{261}$ residues of $\mathrm{CcoA}$ are essential for its function, likely forming its intramembrane $\mathrm{Cu}$ binding site. However, this study was less informative about the role(s) of the remaining $M_{237}$ and $M_{265}$ residues of the CcoA conserved motifs (17). To further pursue this issue, a double mutant $\left(M_{237} A+M_{265} A\right)$ lacking both of these Met residues was obtained, and its properties were compared to the corresponding single mutants. Both Escherichia coli (Fig. 2A) and R. capsulatus (Fig. $2 B$ ) cells harboring the double mutant $M_{237} A+M_{265} A$ produced $C c 0 A$ variant proteins at wild-type levels. The direct effects of these mutations on CcoAdependent $\mathrm{Cu}$ uptake were determined by monitoring radioactive ${ }^{64} \mathrm{Cu}$ accumulation in whole cells (see Materials and Methods). Both $E$. coli and $R$. capsulatus cells producing this $\mathrm{CcoA}$ variant were deficient for ${ }^{64} \mathrm{Cu}$ uptake (Fig. $3 \mathrm{~A}$ and $\mathrm{B}$ ), similar to those mutants lacking CcoA. The $c b b_{3}$-Cox activity of the double mutant was also very low ( 2\% of wild type), in contrast to $\sim 73 \%$ and $\sim 35 \%$ of the single $\mathrm{M}_{237} \mathrm{~A}$ and $\mathrm{M}_{265} \mathrm{~A}$ mutants, respectively (Table 1). The $R$. capsulatus strain lacking a chromosomal copy of $c c 0 A$ and complemented with a plasmid-borne wild type allele $(\triangle c c o A /$ plasmid-born $c c 0 A$ ) (see Table $S 1$ in the supplemental material) was used as a control and exhibited a $c b b_{3}$-Cox activity of $846 \pm 32 \mu \mathrm{mol}$ of tetramethyl-p-phenylenediamine (TMPD) oxidized $/ \mathrm{min} / \mathrm{mg}$ of total membrane proteins (referred to as $100 \%$ in Table 1). Considering that the CcoA variant lacking both $M_{237}$ and $M_{265}$ residues was unable to import $C u$ and produce active $c b b_{3}$-Cox, we concluded that at least one additional Met residue (preferentially $M_{265}$, suggested by its more severe phenotype) located three residues apart from the $\mathrm{M}_{233}$ or $\mathrm{H}_{261}$ on $\mathrm{TMH} 7$ or $\mathrm{TMH} 8$, respectively, is required for $\mathrm{Cu}$ import, probably as a $\mathrm{Cu}$ binding ligand.

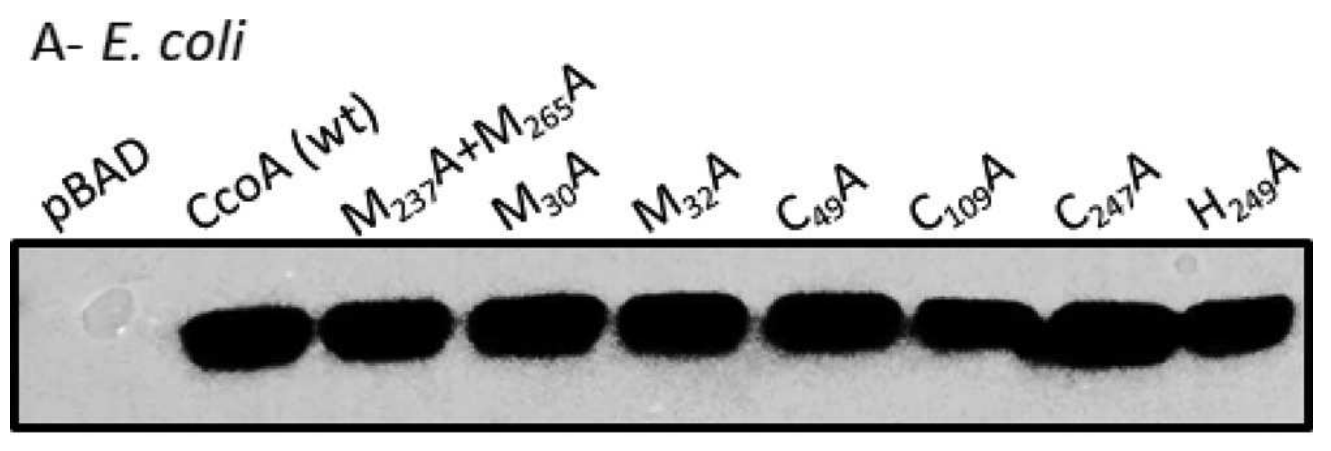

B- $R$. capsulatus

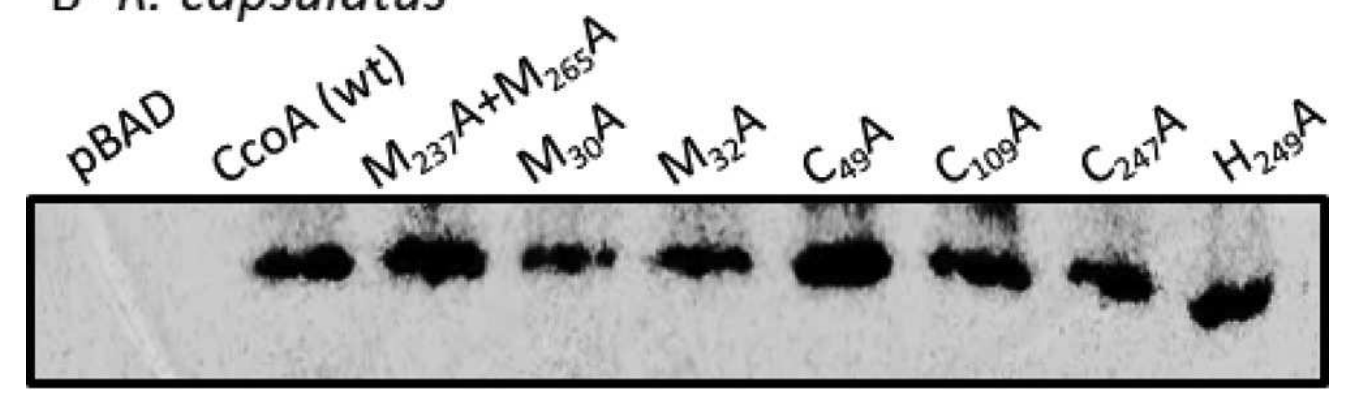

FIG 2 Production of mutant CcoA variants in E. coli and R. capsulatus. Membranes prepared from L-ara induced E. coli (LMG194) (A) and R. capsulatus $\triangle c c 0 A$ (SE8) (B) strains harboring appropriate plasmids (see Table S1) expressing wild-type or indicated CcoA mutant variants were probed with anti-Myc monoclonal antibodies. PBAD and CcoA (wt) correspond to 
membranes prepared from E. coli $(\mathrm{A})$ or $R$. capsulatus $(\mathrm{B})$ strains harboring empty pBAD (E. coli) or pRK-pBAD (R. capsulatus) expression plasmids, and their derivatives containing Myc-tagged versions of wild-type and mutant $c c 0 A$ alleles, as appropriate. All native and mutant proteins were produced adequately in both backgrounds.
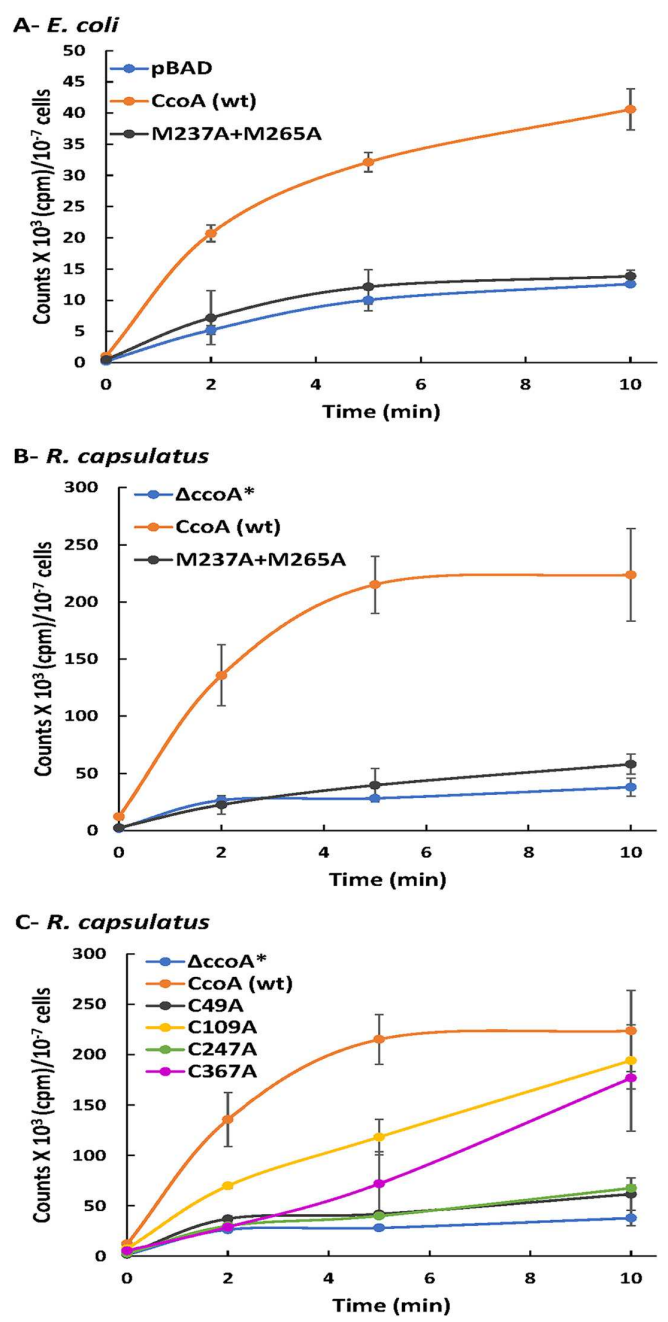

FIG 3 Whole-cell radioactive ${ }^{64} \mathrm{Cu}$ uptake by $\mathrm{C} c 0 \mathrm{~A} \mathrm{M}_{237} \mathrm{~A}+\mathrm{M}_{265} \mathrm{~A}$ double and Cys single mutant derivatives. (A to $C){ }^{64} \mathrm{Cu}$ uptake kinetics observed with the $\mathrm{Cco} A \mathrm{M}_{237} \mathrm{~A}+\mathrm{M}_{265} \mathrm{~A}$ double mutant and $\mathrm{C}_{49} \mathrm{~A}, \mathrm{C}_{109} \mathrm{~A}, \mathrm{C}_{247} \mathrm{~A}$, and $\mathrm{C}_{367} \mathrm{~A}$ single mutants using appropriate L-ara induced $\mathrm{E}$. coli (LMG194) (A) and $R$. capsulatus $\triangle c c o A^{*}(\triangle c c o A \triangle \operatorname{cop} A$, SE24) (B and C) cells, expressing L-ara-inducible native and mutant $c c o A$ alleles. $\mathrm{PBAD}$ and $\triangle c c o A$ refer to control strains, as appropriate. Uptake assays were performed as described in Materials and Methods. Activities measured in cells kept on ice were subtracted from those measured in cells incubated at $37^{\circ} \mathrm{C}$, and assays were repeated at least three times using multiple independent cultures. CcoA (wt) refers to $(\triangle c c 0 A+$ plasmid-borne $c c 0 A)$ strain carrying L-ara-inducible native $\mathrm{CcoA}$, where $\triangle c c o A^{*}$ is $\triangle c c o A \triangle C O P A$ (SE24), used to avoid frequent CopA revertants seen with a $c c 0 A$ deletion (see Table S1) (12). Error bars correspond to the standard deviations around the mean values. In each case, at least three biological and three technical repeats were performed.

\begin{tabular}{|c|c|c|c|c|}
\hline Strain & $\begin{array}{l}\text { Residue } \\
\text { location }^{b}\end{array}$ & \multicolumn{2}{|l|}{ Conservation $(\%)^{c}$} & $c b b_{3}$-Cox activity \\
\hline \multicolumn{5}{|c|}{ Residues located in the conserved motifs of $\mathrm{CcoA}^{a}$} \\
\hline SE8 $(\Delta c c o A)^{*}$ & NA & NA & NA & 2 \\
\hline$M_{233} A^{*}$ & $\mathrm{TMH7}$ & 100 & 100 & 9 \\
\hline$M_{237} A^{*}$ & TMH7 & 100 & 100 & 73 \\
\hline$M_{237} A+M_{265} A$ & TMH7+THM8 & 100 & 100 & 2 \\
\hline \multicolumn{5}{|c|}{ Residues located elsewhere in CcoA } \\
\hline $\mathrm{M}_{30} \mathrm{~A}$ & TMH1 & 90 & 10 & 78 \\
\hline $\mathrm{M}_{32} \mathrm{~A}$ & TMH1 & 80 & 0 & 72 \\
\hline$M_{69} A$ & $\mathrm{TMH} 2$ & 0 & 0 & 88 \\
\hline $\mathrm{C}_{49} \mathrm{~A}$ & $p$ end of $\mathrm{TMH} 2$ & 80 & 0 & 37 \\
\hline $\mathrm{C}_{109} \mathrm{~A}$ & $p$ end of TMH4 & 0 & 70 & 75 \\
\hline $\mathrm{C}_{225} \mathrm{~A}$ & TMH7 & 100 & 20 & 70 \\
\hline $\mathrm{C}_{247} \mathrm{~A}$ & $p$ side loop & 100 & 50 & 6 \\
\hline
\end{tabular}


Additional possible metal-liganding CcoA residues of functional importance. CcoA is rich in Met, His, and Cys residues that can act as potential metal ligands (10), and those that are not parts of the conserved motifs were examined for their possible role(s). Two different amino acid sequence alignments were used with the proteobacterial homologs of $\mathrm{CcoA}$ that contributed to building the protein similarity network of the CalT subfamily (13). The $R$. capsulatus CcoA sequence was first aligned with its closely related CcoA homologs among the Rhodobacterales (mostly from node 1 [see reference 13]) (see Fig. S1). This comparison included $R$. sphaeroides CcoA known to provide $\mathrm{Cu}$ to $c b b_{3}$-Cox (16). The $R$. capsulatus CcoA sequence was also aligned with its more distant homologs among the different proteobacterial orders, including Rhizobiales, Burkhorderiales, Pseudomonales, Rhodospirales, Vibrionales, Oceanospiralles, Synecchocales, Alteromonadales, and Chromatiales (see Fig. S2). This group included Ochrobactrum anthropi (Rhizobiales) CalT (CcoA ortholog) shown to transport $\mathrm{Cu}$ (13) and possibly required for the maturation of cuproproteins distinct from $c b b_{3}$-Cox. Based on sequence alignments and topological locations (i.e., TMH or loop; Table 1) five Met $\left(M_{30}, M_{32}, M_{69}, M_{73}\right.$, and $\left.M_{227}\right)$, possibly forming the $\mathrm{M}_{30} \times \mathrm{M}_{32}$ and $\mathrm{M}_{69} \times x \times \mathrm{M}_{73}$ motifs (of which $\mathrm{M}_{30}$ and $\mathrm{M}_{73}$ are better conserved), two His $\left(\mathrm{H}_{249}\right.$ and $\left.\mathrm{H}_{274}\right)$, and five Cys $\left(\mathrm{C}_{49}, \mathrm{C}_{109}, \mathrm{C}_{225}, \mathrm{C}_{249}\right.$ and $\left.\mathrm{C}_{367}\right)$ residues were retained for this study (Fig. 1, middle and right panels). They were substituted with Ala using L-ara-inducible $\operatorname{cco} A$, and the mutants obtained were introduced into appropriate $E$. coli and $R$. capsulatus strains (see Materials and Methods; Table S1). Their $c b b_{3}-\mathrm{Cox}$ and ${ }^{64} \mathrm{Cu}$ uptake activities were determined analogously to the conserved motifs mutants (17).

Properties of CcoA Met and His mutants. The CcoA single Met $\left(M_{30} A\right.$, $M_{32} A, M_{69} A, M_{73} A$, and $M_{227} A$ ) mutants were produced in amounts similar to the wild type and $\mathrm{M}_{237} \mathrm{~A}+\mathrm{M}_{265} \mathrm{~A}$ double mutant in both $E$. coli and $R$. capsulatus strains (Fig. 2, since the data are identical for all mutants tested, only $M_{30} A$ and $M_{32} A$ are shown). Of these residues, the $M_{30}, M_{32}, M_{69}$, and $M_{73}$ form the socalled "Met (MxM and MxxxM) motifs," sometimes implicated in binding $\mathrm{Cu}(\mathrm{I})(20)$. The single $M_{30} A, M_{32} A$, and $M_{69} A$ mutants on the $N$-ter domain and the $M_{227} A$ single mutant located close to the $\mathrm{M}_{233} \times x \times M_{237}$ putative $\mathrm{Cu}$ binding motif on $\mathrm{TMH} 7$ had $c_{3} b_{3}-\mathrm{Cox}$ activities slightly lower than that of wild-type CcoA (approximately $78,72,88$, and $75 \%$ of wild-type amounts, respectively), similar to the single mutant $\mathrm{M}_{237} \mathrm{~A}(\sim 73 \%)$ (Table 1). In contrast, mutating $\mathrm{M}_{73}$ that is located near the cytoplasmic end of $\mathrm{TMH} 2$ and highly conserved among the Rhodobacteriales CcoA homologs, led to a markedly lower $c b b_{3}$-Cox activity ( 29\%) like the single mutant $\mathrm{M}_{265} \mathrm{~A}$ ( 35\%) (Table 1) (17). The His249 and $\mathrm{H}_{274}$ are near the periplasmic and cytoplasmic ( $p$ and $n$ ) sides of the membrane, respectively, and only the latter residue is conserved in Rhodobacteriales (see Fig. S1). The corresponding mutants had $c b b_{3}-\mathrm{Cox}$ activities slightly lower than the wild type (ca. 87 and $71 \%$, respectively) (Table 1). Thus, unlike $\mathrm{M}_{233}$ and $\mathrm{H}_{261}$, none of these Met and His residues were required for CcoA function, except $\mathrm{M}_{73}$ located close to the cytoplasm, as its substitution significantly reduces $c b b_{3}-\mathrm{Cox}$ activity.

Properties of CcoA Cys mutants. Of the five Cys residues of CcoA, four (except $\mathrm{C}_{109}$ ) are well-conserved especially among the Rhodobacteriales (see Fig. S1). Based on the homology model of $\mathrm{CcoA}(\mathrm{CcoA}$ YajR) obtained using its 
highest homolog E. coli YajR (PDB 3WDO) as a template, the $\mathrm{C}_{49}$ and $\mathrm{C}_{367}$ residues are at or near the periplasmic ends of the $\mathrm{TMH} 2$ and $\mathrm{TMH} 11$, respectively, while $\mathrm{C}_{247}$ is located on a periplasmic loop between $\mathrm{TMH} 7$ and TMH8 (Fig. 1, right panel) $(10,17)$. The nonconserved $\mathrm{C}_{109}$ on $\mathrm{TMH}$, and the partly conserved $\mathrm{C}_{225}$ on $\mathrm{TMH} 7$ are more deeply embedded into the membrane, closer to the $p$ and $n$ sides, respectively. Substitution of each of these Cys residues with Ala did not affect the production of mutant proteins either in $E$. coli or R. capsulatus (Fig. 2; only $\mathrm{C}_{49}, \mathrm{C}_{109}$, and $\mathrm{C}_{247}$ are shown). However, it impaired the $c b b_{3}$-Cox activity of the mutant strains to different extents (Table 1). While the effects of $C_{109} A, C_{225} A$, and $C_{367} A$ mutations were milder (ca. 75, 70, and $\sim 69 \%$ of wild-type activity, respectively), those of the $\mathrm{C}_{49} \mathrm{~A}$ and $\mathrm{C}_{247} \mathrm{~A}$ were more severe (ca. 37 and $\sim 6 \%$, respectively). In respect to $\mathrm{Cu}$ import, upon L-arabinose (L-ara) addition radioactive ${ }^{64} \mathrm{Cu}$ accumulation in whole cells of a control strain lacking CcoA but harboring a plasmid-borne inducible $\mathrm{CcoA}(\triangle c c o A+$ plasmid-borne $c c 0 A)$ steadily increased, unlike the $\triangle c c 0 A$ strain lacking $\mathrm{CcoA}$. With the $\mathrm{C}_{49} \mathrm{~A}$ or $\mathrm{C}_{247} \mathrm{~A}$ mutants, ${ }^{64} \mathrm{Cu}$ accumulation was very low, similar to the strain lacking $\mathrm{CcoA}$, indicating that these residues are critical for CcoA function (Fig. 3C). On the other hand, the $\mathrm{C}_{109} \mathrm{~A}$ and $\mathrm{C}_{367} \mathrm{~A}$ mutants accumulated ${ }^{64} \mathrm{Cu}$ markedly more slowly to a slightly lower level than the control cells, indicating that $\mathrm{C}_{109}$ and $\mathrm{C}_{367}$ also contribute to $\mathrm{Cu}$ uptake but are not essential. Overall, the data indicated that these mutants fall into two groups $\left(C_{49} A\right.$ and $C_{247} A$ versus $C_{109} A$ and $\left.C_{367} A\right)$ with distinct kinetics behaviors, suggesting likely different functions.

Topological locations of periplasm-facing Cys residues of CcoA. Currently, no 3D structure of CcoA is available beyond the CcoAYajR homology model (Global Model Quality Estimate [GMQE] 0.51) based on its most pronounced homolog, which is the E. coli YajR (PDB 3WDO) (17). Fortunately, additional homology models of CcoA of similar GMQE yielding similar outcomes can be generated using available X-ray structures, including the iron exporter BpFPN (21). Here, we opted for two of its importer homologs, LacY (PDB 6C9W,

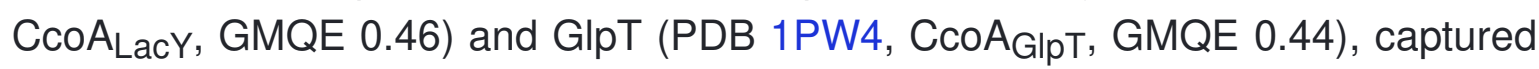

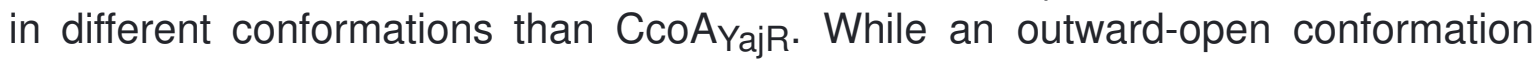
(i.e., ready to receive the substrate from the $p$ side of the membrane) is seen with $\mathrm{CcoA}_{\text {YajR }}$, the $\mathrm{Cco} \mathrm{A}_{\mathrm{Lac}}$ and $\mathrm{CcoA}_{\mathrm{GlpT}}$ models provide the occluded and the inward-open (i.e., ready to release the substrate to the $n$ side of the membrane) conformations, respectively (Fig. 4A). Top views of these models clearly show that the distances separating the periplasm facing Cys residues change drastically depending on the conformations (Fig. 4B; see also Table S3, which lists all appropriate $\alpha-C$-to- $\alpha-C$ distances). When $\mathrm{CcoA}_{Y a j \mathrm{R}}$ is in the outward-open conformation (Fig. 4B top), $\mathrm{C}_{49}$ and $\mathrm{C}_{109}$ located on the $\mathrm{N}$-ter domain are very close to each other $\left(\mathrm{C}_{49}-\mathrm{C}_{109}, 12 \AA\right)$ and distant from $\mathrm{C}_{247}\left(\mathrm{C}_{49}-\mathrm{C}_{247}, 32 \AA ; \mathrm{C}_{109}\right.$ $\left.\mathrm{C}_{247}, 39 \AA\right)$ and $\mathrm{C}_{367}\left(\mathrm{C}_{49}-\mathrm{C}_{367}, 22 \AA ; \mathrm{C}_{109}-\mathrm{C}_{367}, 32 \AA\right)$ located on the C-ter domain. In the occluded conformation of $\mathrm{CcoA}_{\mathrm{Lac}}$ (Fig. 4B, middle), $\mathrm{C}_{49}$ moves closer to $\mathrm{C}_{247}\left(\mathrm{C}_{49}-\mathrm{C}_{247}, 23 \AA\right)$ and $\mathrm{C}_{367}\left(\mathrm{C}_{49}-\mathrm{C}_{367}, 16 \AA\right)$, while $\mathrm{C}_{109}$ shifts closer to both $\mathrm{C}_{247}$ and $\mathrm{C}_{367}\left(\mathrm{C}_{109}-\mathrm{C}_{247}, 36 \AA ; \mathrm{C}_{109}-\mathrm{C}_{367}, 28 \AA\right)$. In the inward-open conformation of $\mathrm{Cco}_{\mathrm{GlpT}}$ (Fig. 4B, bottom), $\mathrm{C}_{49}$ and $\mathrm{C}_{109}$ approach even closer to $\mathrm{C}_{247}\left(\mathrm{C}_{49}-\mathrm{C}_{247}, 16 \AA ; \mathrm{C}_{109}-\mathrm{C}_{247}, 27 \AA\right)$ and $\mathrm{C}_{367}\left(\mathrm{C}_{49}-\mathrm{C}_{367}, 10 \AA ; \mathrm{C}_{109}-\mathrm{C}_{367}\right.$, $22 \AA$ ). In all conformations, the N-ter-located $\mathrm{C}_{49}-\mathrm{C}_{109}$ pair stays within 12 to $14 \AA$, and the $\mathrm{C}$-ter-located $\mathrm{C}_{247}-\mathrm{C}_{367}$ pair remains within 19 to $22 \AA$ of each other. Indeed, these distance estimations are approximations in the absence of $3 D$ 
structures. Nonetheless, they depict the progressive movement of the $\mathrm{N}$-ter domain $\mathrm{C}_{49}$ toward the $\mathrm{C}$-ter domain $\mathrm{C}_{247}-\mathrm{C}_{367}$ pair during the transition from the outward-open to the inward-open conformations. This observation enticed us to inquire whether the predicted distance changes are related to the Cys residues that are exposed to the oxidizing periplasm undergoing thiol:disulfide oxidoreduction during CcoA function.
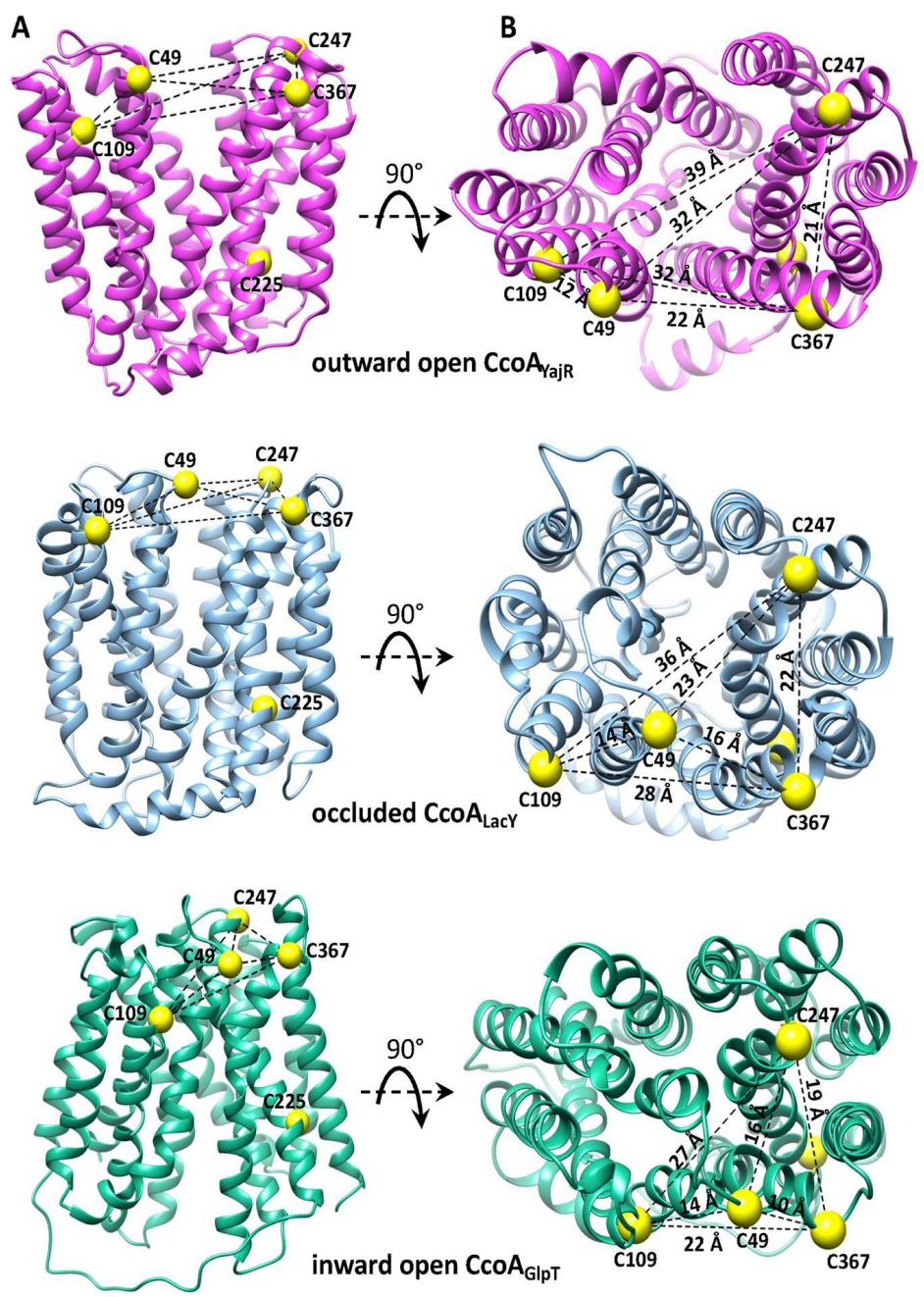

FIG 4 Different CcoA conformations and the distances that separate the periplasmic Cys residues in each conformational state. (A) Side views of $R$. capsulatus CcoA homology models $\left(\mathrm{CCOA}_{Y a j R}, \mathrm{Cco} \mathrm{A}_{\mathrm{Lac}}\right.$, and $\mathrm{CCOA}_{\mathrm{GlpT}}$ ) representing its different conformations using as the templates E. coli YaJR (3WDO) in the outward-facing state (16\% identity; GMQE 0.51), lactose permease LacY (1PV6) in the occluded state (12.7\% identity; GMQE 0.41), and GlpT (1PW4) in the inward-facing state (11.7\% identity; GMQE 0.46) (http://swissmodel.expasy.org). (B) Top views of the homology models shown in panel $A$, with the distances separating the periplasmfacing Cys residues (yellow balls) in different conformations of CcoA.

Disulfide bonds formed between the Cys residues of CcoA. The occurrence in vivo of disulfide bond(s) in CcoA was probed using E. coli cells expressing native $\mathrm{CcoA}$ or its Cys mutant variants and the thiol-reactive alkylating agent monomethyl-(PEG)24-maleimide (mPEG) (22). Alkylation of free Cys thiols of CcoA by mPEG is expected to increase its molecular weight (MW) by $\sim 1.2 \mathrm{kDa}$ per free thiol. In the case of disulfide bonds, alkylation occurs only after reduction by dithiothreitol (DTT), and then MPEG further increases the MW by $\sim 2.4 \mathrm{kDa}$ per reduced disulfide bond. The relative MW changes $\left(M_{\mathrm{r}}\right)$ in native and Cys mutant variants of CCOA were followed by SDS-PAGE/immunodetection (Fig. 5 and 6).

\begin{tabular}{|c|c|c|c|c|}
\hline \multicolumn{2}{|c|}{$\operatorname{CoOA}$} & \multicolumn{2}{|c|}{ CcoA Cys mutants } & \multirow[b]{2}{*}{ Identified } \\
\hline.$D T$ & $+D T T$ & .DTT & $+D T$ & \\
\hline
\end{tabular}




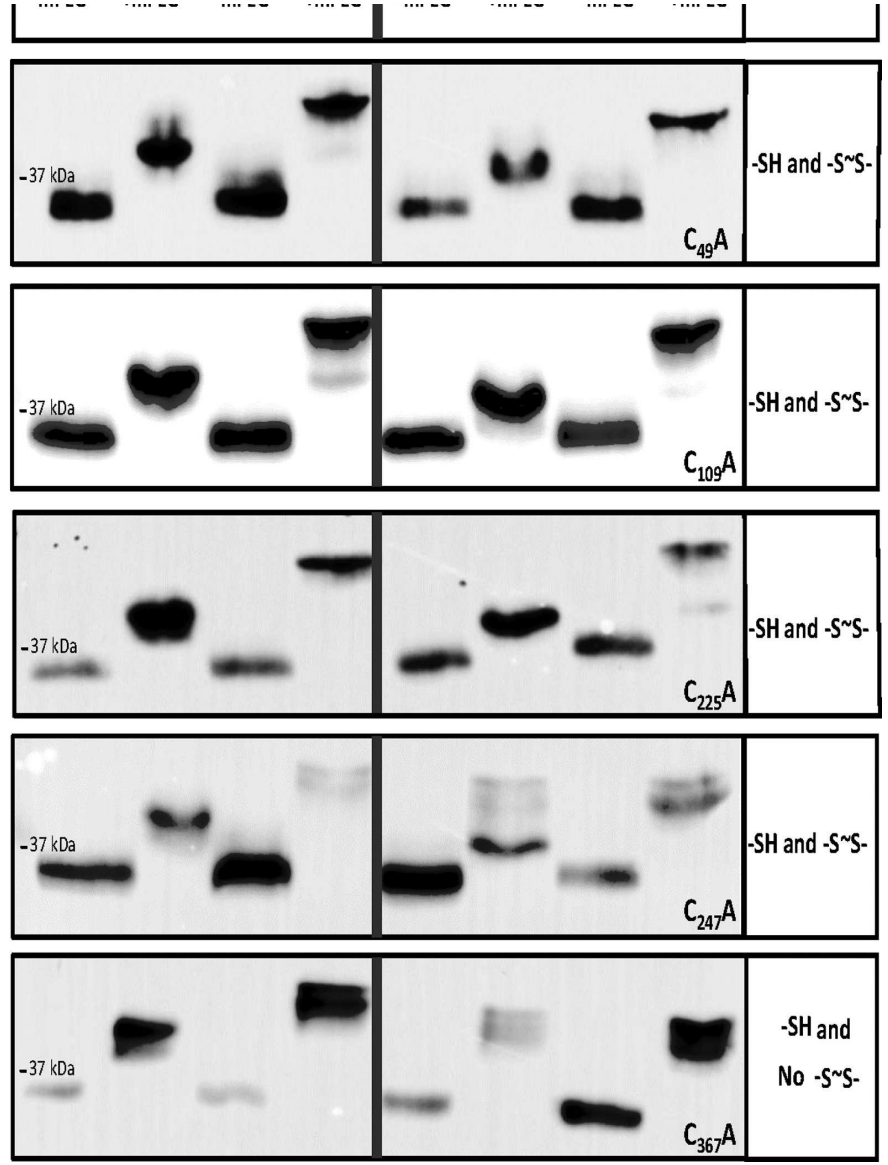

FIG 5 In vivo free thiols and disulfide bonds in native CcoA and its single Cys mutant derivatives. SDS-PAGE, followed by immunoblot analysis of $E$. coli cells expressing native and single $\mathrm{C}_{49} \mathrm{~A}$, $\mathrm{C}_{109} \mathrm{~A}, \mathrm{C}_{225} \mathrm{~A}, \mathrm{C}_{247} \mathrm{~A}$, and $\mathrm{C}_{367} \mathrm{~A}$ mutant variants of $\mathrm{CcoA}$. Cells growing in the presence of $\mathrm{L}$-ara were treated mid-log phase for $10 \mathrm{~min}$ with or without DTT, followed by TCA precipitation and subsequent alkylation with or without MPEG. The presence of unmodified or MPEG alkylated CcoA was detected using anti-Myc monoclonal antibody and horseradish peroxidase conjugated anti-mouse IgG (see Materials and Methods). The total protein amounts of SDS-solubilized TCAprecipitated pellets could not be determined precisely, leading to variations of protein amounts loaded per lane. Thus, only the qualitive occurrence of $M_{\mathrm{r}}$ shifts in the absence or presence of DTT or MPEG were taken into consideration in this experiment.

\begin{tabular}{|c|c|c|c|c|c|c|c|c|}
\hline \multicolumn{4}{|c|}{ CCOA } & \multicolumn{4}{|c|}{ CCOA Cys mutants } & \multirow{3}{*}{$\begin{array}{l}\text { Identified } \\
\text {-SH and -S S- }\end{array}$} \\
\hline \multicolumn{2}{|c|}{-DTT } & \multicolumn{2}{|c|}{ +DTT } & \multicolumn{2}{|c|}{-DTT } & \multicolumn{2}{|c|}{ +DTT } & \\
\hline -mPEG & +mPEG & -mPEG & + PPEG & -mPEG & +mPEG & -mPEG & +mPEG & \\
\hline
\end{tabular}
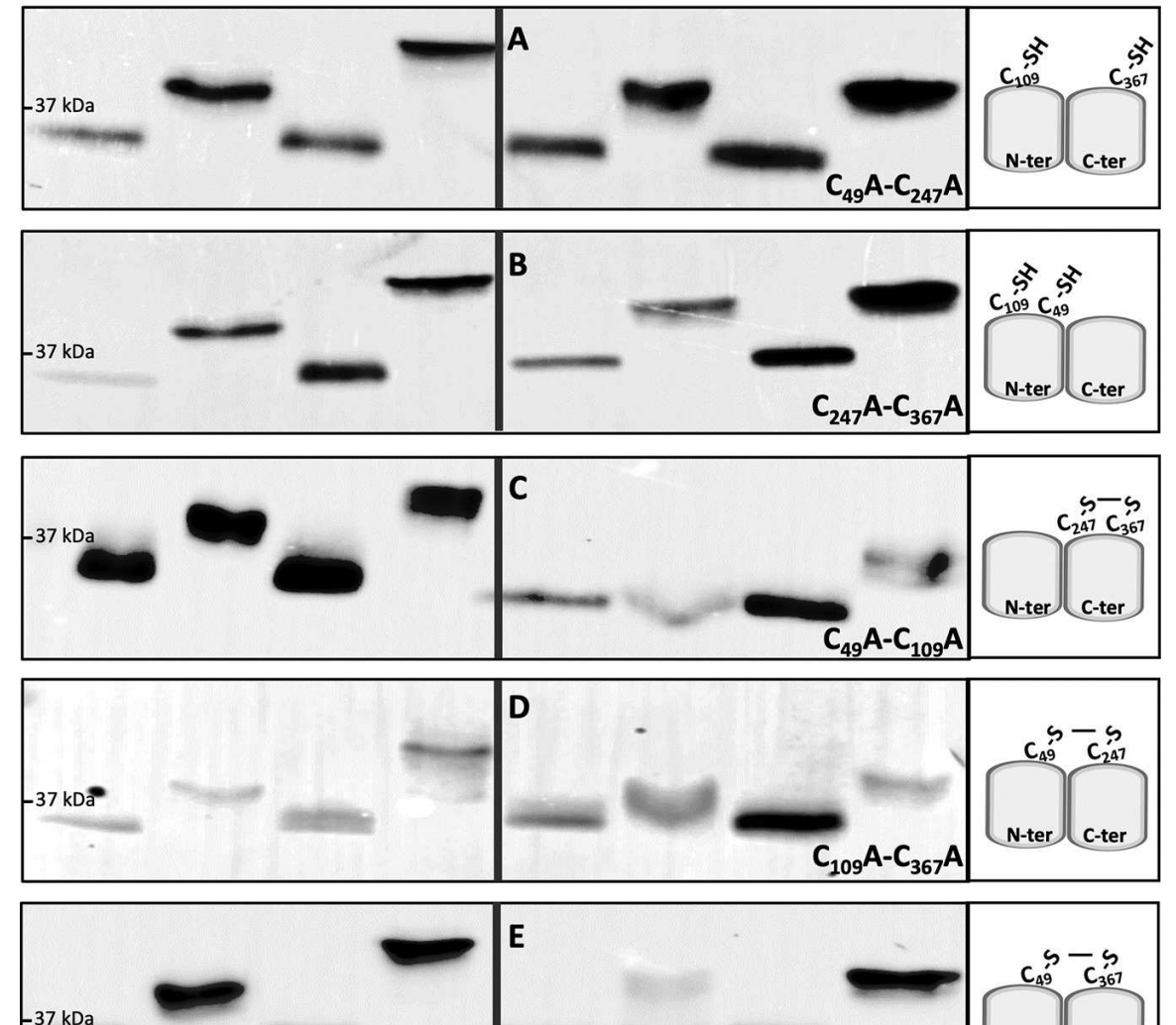
FIG 6 In vivo free thiols and disulfide bonds formed in native CcoA and its double Cys mutant derivatives. The experiments were conducted as described in Fig. 5, except that E. coli cells expressing the native (left side panels) and double mutant variants of $\mathrm{CcoA}$ were used: $\mathrm{C}_{49} \mathrm{~A}$ $C_{247} A(A), C_{247} A-C_{367} A(B), C_{49} A-C_{109} A(C), C_{109} A-C_{367} A(D)$, and $C_{109} A-C_{247} A(E)$. As in Fig. 5, the total protein amounts of SDS-solubilized TCA-precipitated pellets could not be determined precisely, leading to variations of protein amounts loaded per lane. Thus, only the $M_{r}$ shifts detected in the absence or presence of DTT or MPEG were considered in these experiments.

Under our conditions, native CcoA (predicted MW of $37.4 \mathrm{kDa}$ ) runs as a band of $\sim 35-\mathrm{kDa} M_{\mathrm{r}}$ in its oxidized or reduced forms (Fig. 5, left panels), which is not uncommon for membrane proteins. In the absence of DTT, alkylating by $\mathrm{mPEG}$ increased native CcoA $M_{r}$ by ca. 3 to $4 \mathrm{kDa}$ to ca. 38 to $39 \mathrm{kDa}$, suggesting that it contained three free Cys thiols (predicted $M_{r}$ of $38.6 \mathrm{kDa}$ after three $\mathrm{mPEG}$ addition). Moreover, alkylating native CcoA after DTT reduction further increased its $M_{r}$ by another $\sim 2-3 \mathrm{kDa}$ to ca. 40 to $41 \mathrm{kDa}$, indicating that the native protein contained one disulfide bound in vivo (Fig. 5, left panels). Although detecting the ca. 1- to 2-kDa $M_{r}$ differences with hydrophobic membrane proteins was challenging, following TCA precipitation all CcoA Cys residues appeared accessible to alkylation, including the $\mathrm{Cys}_{109}$ and $\mathrm{Cys}_{225}$, which are more buried into the lipid bilayer according to the CcoA structural models (Fig. 1 and 4).

Similar mPEG alkylation experiments were repeated using single Cys mutant variants of $\mathrm{CcoA}$ (Fig. 5, right panels). Without DTT reduction, all single Cys mutant variants exhibited mPEG-induced $M_{r}$ shifts similar to native CcoA, and the largest shift was seen with $\mathrm{C}_{367} \mathrm{~A}$ mutant. In all cases but $\mathrm{C}_{367} \mathrm{~A}$, the shifts were consistent with the likely presence of at least two free thiols, but not four as would have been expected upon elimination of any Cys residues already engaged in a disulfide bond in native CcoA. After DTT reduction, all single Cys mutants, except $\mathrm{C}_{367} \mathrm{~A}$, showed the additional $\mathrm{mPEG}$-induced $M_{\mathrm{r}}$ shifts, indicating that they still contained a disulfide bond formed among the remaining Cys residues. This observation suggested that native $\mathrm{CcoA}$ has more than two Cys residues that could form a disulfide bond(s). The $\mathrm{C}_{367} \mathrm{~A}$ mutant was intensely alkylated but did not exhibit any readily detected MPEG-mediated $M_{r}$ shift after DTT reduction, indicating that it contained no more disulfide bonds, and suggested that this residue provides one of the thiol groups forming a stable disulfide bond in native CcoA (Fig. 5, right panel, last row). Although occasionally additional minor bands were also seen in some cases (e.g., native CcoA, Fig. 5 left panel, second row, or $\mathrm{C}_{225} \mathrm{~A}$, Fig. 5 right panel, third row), the data showed that the $\mathrm{C}_{49} \mathrm{~A}, \mathrm{C}_{109} \mathrm{~A}, \mathrm{C}_{225} \mathrm{~A}$, or $\mathrm{C}_{247} \mathrm{~A}$ single Cys mutants behaved similarly to each other and to native CcoA, which precluded identification of partner cysteines for forming a disulfide bond.

To identify the disulfide bond forming partner(s) in native CcoA in vivo, a set of double Cys mutants were examined (Fig. 6). All CcoA double Cys variants were produced adequately in $E$. coli and in $R$. capsulatus and exhibited low $c b_{3}-\mathrm{Cox}$ activities like their cognate single Cys mutants. In the absence of DTT, mPEG alkylation data showed that the double mutants $C_{49} A-C_{247} A$ (with $C_{109}, C_{225}$, and $\mathrm{C}_{367}$ intact) and $\mathrm{C}_{247} \mathrm{~A}-\mathrm{C}_{367} \mathrm{~A}$ (with $\mathrm{C}_{49}, \mathrm{C}_{109}$, and $\mathrm{C}_{225}$ intact) had $M_{\mathrm{r}}$ shifts similar to each other, and to native CcoA, containing free thiols (Fig. 6A and B). However, like the $\mathrm{C}_{367}$ single mutant (Fig. 5, bottom row), these two double Cys mutants did not exhibit any additional mPEG-induced $M_{r}$ increase upon reduction 
by DTT, indicating that the remaining Cys residues did not form disulfide bonds. Conversely, the double mutants $\mathrm{C}_{49}-\mathrm{C}_{109}$ (with $\mathrm{C}_{225}, \mathrm{C}_{247}$, and $\mathrm{C}_{367}$ intact) and $\mathrm{C}_{109}-\mathrm{C}_{367}$ (with $\mathrm{C}_{49}, \mathrm{C}_{225}$, and $\mathrm{C}_{247}$ intact) showed no or slight mPEG-induced $M_{\mathrm{r}}$ shifts in the absence of DTT (although the absence of this shift was less clear in the latter double mutant) but exhibited clearer $M_{\mathrm{r}}$ shifts upon $\mathrm{mPEG}$ alkylation after DTT treatment (Fig. $6 \mathrm{C}$ and D). Since the $\mathrm{C}_{225}$ residue is near the $n$ side and remote from the other periplasm-exposed Cys residues on the $p$ side of the membrane, it is likely that in the $\mathrm{C}_{49} \mathrm{~A}-\mathrm{C}_{109} \mathrm{~A}$ and $\mathrm{C}_{109} \mathrm{~A}-\mathrm{C}_{367} \mathrm{~A}$ double mutants, the $\mathrm{C}_{247}$ and $\mathrm{C}_{367}$ and the $\mathrm{C}_{49}$ and $\mathrm{C}_{247}$ residues, respectively, formed disulfide bonds (although the latter pair might form a less stable disulfide bond) (Fig. 6C and $\mathrm{D}$, far right). The slight $M_{\mathrm{r}}$ shifts seen with these double mutants in the absence of DTT reduction were consistent with the poor alkylation of $C_{225}$, still intact in these mutants. The remaining $\mathrm{C}_{109} \mathrm{~A}-\mathrm{C}_{247} \mathrm{~A}$ double mutant (with $\mathrm{C}_{225}$, $\mathrm{C}_{49}$, and $\mathrm{C}_{367}$ intact) behaved essentially like the latter mutants, except that the CcoA population appeared heterogenous in the absence of DTT (Fig. 6E). A small fraction contained free thiols that was alkylated by MPEG without DTT treatment, whereas a large fraction contained a disulfide bond that could only be alkylated after DTT reduction. Again, assuming that $\mathrm{C}_{225}$ is too far from the other Cys residues to participate in disulfide bond formation, a large fraction of the $\mathrm{C}_{109} \mathrm{~A}$ $\mathrm{C}_{247} \mathrm{~A}$ double-mutant population comprises a less stable disulfide bond between the $\mathrm{C}_{49}$ and $\mathrm{C}_{367}$ residues (Fig. $6 \mathrm{E}$ ). In summary, the overall data indicated the formation of disulfide bonds between $\mathrm{C}_{49 \sim} \sim \mathrm{C}_{247}, \mathrm{C}_{49} \sim \mathrm{C}_{367}$, and $\mathrm{C}_{247} \sim \mathrm{C}_{367}$ (with the last one forming the most stable bond) and the clear absence of disulfide

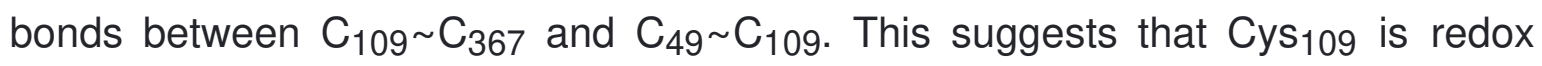
inactive, unlike the other periplasm-exposed residues, possibly due to its membrane-buried location in all conformations of CcoA (Fig. 4). Consequently, in cells producing native $\mathrm{CcoA}$, any pair among the $\mathrm{C}_{49}, \mathrm{C}_{247}$, and $\mathrm{C}_{367}$ residues could form a single disulfide bond in vivo, leaving behind three free thiol groups, including $\mathrm{C}_{109}$ and $\mathrm{C}_{225}$. This finding raised the possibility that native $\mathrm{C} c \mathrm{~A}$ in vivo might exist as a heterogenous population with different conformations, presumably due to the import of spurious Cu presumably present in the growth medium. How the initial binding of $\mathrm{Cu}$ changes the conformation of $\mathrm{CcoA}$ and shuffles the free thiols and disulfide bonds between its three active Cys residues remains to be determined in future studies.

\section{DISCUSSION}

This study focused on the role of plausible metal-liganding residues Met, His and Cys of CcoA, a member of the CalT ( $\underline{C}$ co $\underline{A}$-like Iransporters) subfamily of MFStype transporters (13) and the prototype of proteobacterial $\mathrm{Cu}$ importers $(10,15)$. The CalT subfamily is characterized by two well-conserved motifs $\left(M_{233} \times x \times M_{237}\right.$ and $\mathrm{H}_{261} \times \mathrm{xxM}_{265}$ in $R$. capsulatus $\mathrm{CcoA}$ ) of which the first Met and His residues are absolutely required for $\mathrm{Cu}$ import (17). Here, we show that mutating concomitantly the $M_{237}$ and $M_{265}$ residues also abolishes CcoA activity, unlike the corresponding single mutants. Thus, the presence of at least one additional Met residue together with $\mathrm{Met}_{233}$ and $\mathrm{His}_{261}$ is required for $\mathrm{Cu}$ import. This finding further supports the $\mathrm{Cu}$ binding role of the conserved motifs that are the hallmark of the CalT subfamily of MFS-type transporters $(13,17)$.

We examined the distribution and topological location of additional possible metal-liganding residues of $\mathrm{CcoA}$ that are often conserved among its homologs, in particular those from the Rhodobacterales within the Proteobacteria. Of these 
residues, mutating $\mathrm{C}_{225}, \mathrm{M}_{227}$, or $\mathrm{H}_{274}$ located at the TM7 and TM8 on the $\mathrm{C}$-ter domain of $\mathrm{CcoA}$ near the membrane $\mathrm{Cu}$-binding site, had little effect on CcoA activity. This finding was similar to that seen with the $M_{237} A$ or $M_{265} A$ single mutants, suggesting that they were either not critical for function, or partly substituted by surrogate residues. Intriguingly, mutating $M_{73}$, but not $M_{69}$, of the putative "Met" motif $\left(\mathrm{M}_{69} \times \mathrm{xx}_{73}\right.$ in $R$. capsulatus) (20) had a stronger effect on $c b b_{3}$-Cox activity. Homology models of the different conformations of CcoA do not seem to suggest that these $\mathrm{N}$-ter residues come very close to the $\mathrm{C}$-ter $\mathrm{Cu}$ binding residues. However, how $\mathrm{Cu}$ is released from $\mathrm{CcoA}$ is not yet known, leaving the possibility open that the $\mathrm{C}_{225}, \mathrm{M}_{227}$, and $\mathrm{H}_{274}$ residues or the putative Met $\left(\mathrm{M}_{69} \times x \times M_{73}\right)$ motif, or both, all positioned closer to the $n$ side of the membrane, might play a role in this process.

Remarkably, mutating the periplasm-exposed $\mathrm{C}_{49}, \mathrm{C}_{247}$, and $\mathrm{C}_{367}$ residues affected CcoA activity to different degrees. These residues are well-conserved among the Rhodobacterales, but either less ( $50 \%$ for $\left.\mathrm{C}_{247}\right)$ or not $\left(0 \%\right.$ for $\mathrm{C}_{49}$ and $\mathrm{C}_{367}$ ) conserved in other proteobacterial orders (see Fig. S1 and S2). The basis of this conservation is not obvious, but it might relate to the ultimate destination of $\mathrm{Cu}$ (e.g., cbb3-Cox in $R$. capsulatus and other cuproenzymes in $O$. anthropi) and the different $\mathrm{Cu}$ donors and acceptors of $\mathrm{CcoA}$ and its homologs. Of the periplasm-facing $\mathrm{Cys}\left(\mathrm{C}_{49}, \mathrm{C}_{109}, \mathrm{C}_{247}\right.$, and $\left.\mathrm{C}_{367}\right)$ residues of $\mathrm{Cco} A$, mutating $\mathrm{C}_{109}$ slowed $\mathrm{Cu}$ uptake (Fig. $3 \mathrm{C}$ ), slightly affected $c b b_{3}$-Cox activity (Table 1), and mPEG alkylation indicated that $\mathrm{C}_{109}$ does not form a disulfide bond with either $\mathrm{C}_{367}$ or $\mathrm{C}_{49}$. Intriguingly, $\mathrm{C}_{109}$ residue is not conserved among the Rhodobacterales ( $0 \%$ ) but is better conserved ( $70 \%)$ among the other orders of proteobacteria where CalT is thought to provide $\mathrm{Cu}$ to other cuproproteins distinct from the $c b b_{3}$-Cox (13).

Alkylation data of the single and double Cys mutants revealed that in native CcoA, two of the three periplasm-facing $C_{49}, C_{247}$, and $C_{367}$ residues form a disulfide bond, while the remaining two remain as free thiol in vivo. Moreover, all possible disulfide and free thiol combinations among these residues (i.e., $\mathrm{C}_{247} \sim \mathrm{C}_{367}$ leaving $\mathrm{C}_{49}$ free, $\mathrm{C}_{49} \sim \mathrm{C}_{247}$ leaving $\mathrm{C}_{367}$ free, and $\mathrm{C}_{49} \sim \mathrm{C}_{367}$ leaving $\mathrm{C}_{247}$ free) were observed in appropriate Cys double mutants. However, the levels of stability of these bonds seem to be different, with the $\mathrm{C}_{247} \sim \mathrm{C}_{367}$ bond being most stable. Although the data in Fig. 6 tend to suggest that the $\mathrm{C}_{49} \sim \mathrm{C}_{247}$ bond might be formed, yet the data with the single $C_{367} A$ mutant (Fig. 5) suggest that it certainly must not be stable to be readily detected in this mutant. Assuming that CcoA undergoes conformational changes like any MFS-type transporter, the disulfide bond formation patterns suggest a hypothetical model linking $\mathrm{Cu}$ binding and conformational changes (Fig. 7). Accordingly, in the outward-open conformation of CcoA (state 1), $\mathrm{C}_{247}$ and $\mathrm{C}_{367}$ would contain a disulfide bond, far away from $\mathrm{C}_{49}$. Binding of $\mathrm{Cu}$ would convert $\mathrm{CcoA}$ into its occluded conformation (state 2), bringing $\mathrm{C}_{49}$ near the $\mathrm{C}_{247} \sim \mathrm{C}_{367}$ disulfide bond, and a nucleophilic attack would yield either $\mathrm{C}_{49} \sim \mathrm{C}_{367}$ (Fig. 7, left) or $\mathrm{C}_{49} \sim \mathrm{C}_{247}$ (Fig. 7, right) disulfide bond while freeing the remaining thiol of $\mathrm{C}_{247}$ or $\mathrm{C}_{367}$. We note that if no such disulfide bond is formed or is extremely unstable, then the occluded conformation (state 2) may not have a disulfide bond (not shown in Fig. 7). In the exponentially growing cells used in this study, $\mathrm{Cu}$ import is not synchronized; thus, different conformations of CcoA must coexist, rendering impossible to discriminate between these possibilities at this stage. The more defective phenotype and the periplasmic 
location (i.e., increased solvent exposure) of $\mathrm{C}_{247}$ as well as the weaker nature of

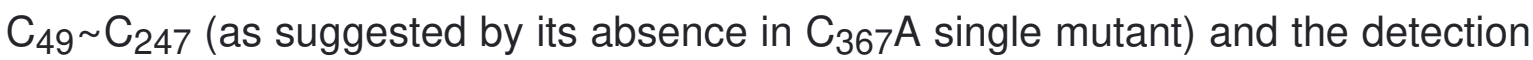
of $\mathrm{C}_{49} \sim \mathrm{C}_{367}$ (as seen with $\mathrm{C}_{109} \mathrm{~A}-\mathrm{C}_{247} \mathrm{~A}$ double mutant) disulfide bonds might argue that the $\mathrm{C}_{49}-\mathrm{C}_{367}$ disulfide bond may be more favorable at the inward open conformation (state 3) (Fig. 7, right). In any case, further progression of $\mathrm{Cu}$ within $\mathrm{C} c 0 \mathrm{~A}$ from the periplasm toward the cytoplasm would trigger the remaining free thiol $\left(\mathrm{C}_{247}\right.$ or $\left.\mathrm{C}_{367}\right)$ to attack the disulfide bond involving $\mathrm{C}_{49}\left(\mathrm{C}_{49} \sim \mathrm{C}_{247}\right.$ or $\mathrm{C}_{49} \sim \mathrm{C}_{367}$ ) at the inward open conformation (state 3). The subsequent resolution of this bond would then reestablish the initial $\mathrm{C}_{247} \sim \mathrm{C}_{367}$ disulfide bond and free $\mathrm{C}_{49}$ thiol, returning $\mathrm{CcoA}$ to its outward-open conformation (state 1). This model attributing more critical roles to $\mathrm{C}_{49}$ and $\mathrm{C}_{247}$ is also consistent with the highly defective ${ }^{64} \mathrm{Cu}$ uptake seen with the $\mathrm{C}_{49} \mathrm{~A}$ and $\mathrm{C}_{247} \mathrm{~A}$ single mutants (Fig. $3 \mathrm{C}$ ). Conceivably, the three periplasm-facing $\mathrm{C}_{49}, \mathrm{C}_{247}$, and $\mathrm{C}_{367}$ residues that are highly conserved in Rhodobacterales may also play additional and perhaps different roles (e.g., liganding $\mathrm{Cu}$ ) instead of those ascribed here. However, this hypothetical model suggests a link between the binding of $\mathrm{Cu}$, ensuing conformation changes, and plausible thiol:disulfide oxidoreduction of CcoA. In this respect, the absence of $R$. capsulatus thiol: disulfide oxidoreductase DsbA (23), which catalyzes intramolecular disulfide bonds in extracytoplasmic proteins, is known to affect $\mathrm{Cbb}_{3}$-Cox biogenesis (24). Whether or not DsbA is involved in these thiol:disulfide exchange reactions seen with CcoA is presently unknown, but future studies addressing determination of the thiol:disulfide exchange reaction rates (e.g., using 5,5-dithio-bis-2-nitrobenzoic acid) (23) and the pKa values of appropriate thiols might identify the attacking and resolving Cys residues to further elucidate this process.
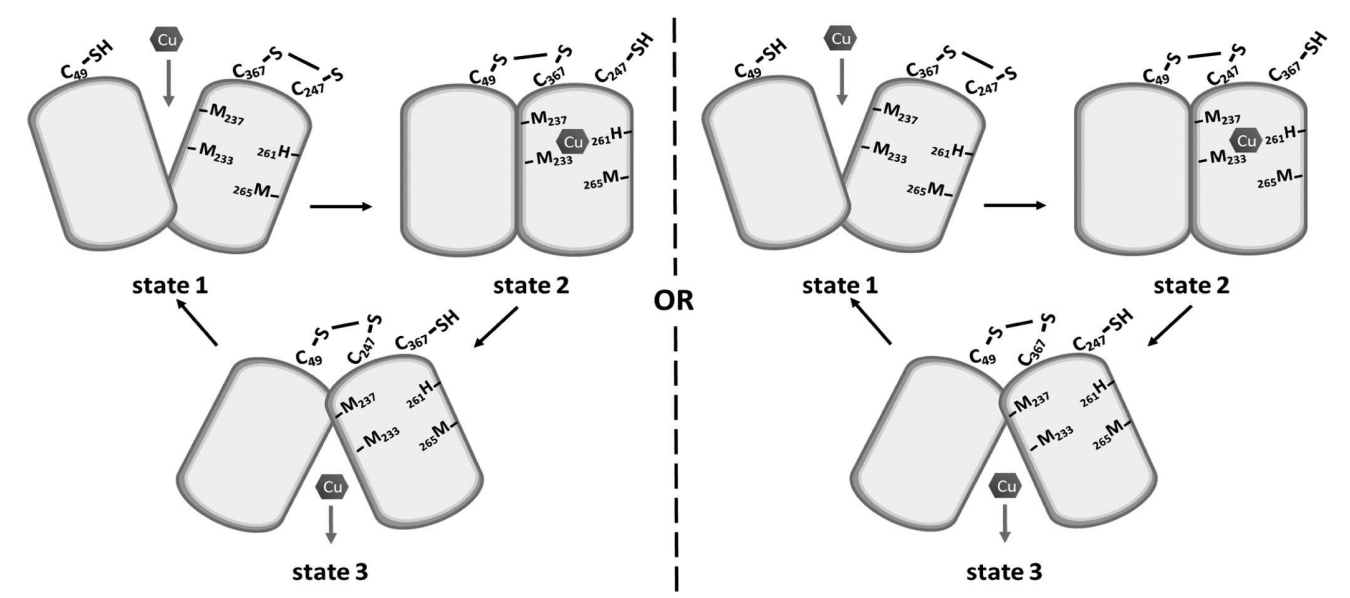

FIG 7 Hypothetical model linking substrate binding, conformational changes, and thiol:disulfide exchange reactions that $\mathrm{CcoA}$ might undergo during $\mathrm{Cu}$ import. Accordingly, at the onset $\mathrm{CcoA}$ has one disulfide $\mathrm{C}_{247} \sim \mathrm{C}_{367}$ and $\mathrm{C}_{49}$-SH (outward open state 1 ), binding of $\mathrm{Cu}$ induces a conformational change leading to occluded state 2, where a $\mathrm{C}_{49 \sim} \sim \mathrm{C}_{367}$ (left side) or a $\mathrm{C}_{49 \sim \mathrm{C}_{247}}$ (right side) disulfide bond is formed (although the available data cannot rule out the absence of a disulfide bond at this state). Exchange of disulfide bonds and progress of $\mathrm{Cu}$ from the $p$ to the $n$ side of the membrane yield the inward open state 3. Upon release of $\mathrm{Cu}$ and resolution of the latter disulfide bond, CcoA is returned to its starting conformation.

Noticeably, other Cu transporters also have critical Cys residues. The Ctr-type transporters contain important Cys residues (within the $\mathrm{HCH}$ motif) at their C-terminal parts, near the $n$ side of the membrane (25). They form disulfide bonds between the monomers of trimeric CTR1 to facilitate $\mathrm{Cu}$ release, unlike the periplasm-facing Cys residues of $\mathrm{CcOA}$ monomer, presumably involved in $\mathrm{Cu}$ uptake. Clearly, a requirement for Met, His, and Cys residues for CcoA activity 
distinguishes its mechanism of function from other well-known $\mathrm{Cu}(\mathrm{I})$ transporters, including the eukaryotic Ctr1 (25-27) or the bacterial CopA and CusA $(28,29)$ proteins.

In summary, we showed here that the periplasm-facing Cys residues, together with the conserved membrane-embedded Cu-binding $\left(\mathrm{M}_{233} x x x M_{237}\right)$ and $\left(\mathrm{H}_{261} \mathrm{xxx} \mathrm{M}_{265}\right)$ motifs, are critical for proper function of the MFS-type $\mathrm{Cu}$ importer CcoA and possibly of its close homologs among Rhodobacterales.

\section{MATERIALS AND METHODS}

Growth conditions, strains, and plasmids used. The bacterial strains used in this work are described in Table $\mathrm{S} 1$ in the supplemental material. Escherichia coli strains were grown at $37^{\circ} \mathrm{C}$ on LB (lysogeny broth or Luria-Bertani) medium, supplemented with antibiotics (100 and $12.5 \mu \mathrm{g} / \mathrm{ml}$ ampicillin [Amp] and tetracycline [Tet], respectively) and L-arabinose (L-ara; 0.5\%), as appropriate (17). The purple nonsulfur facultative photosynthetic $R$. capsulatus strains were grown at $35^{\circ} \mathrm{C}$ under respiratory (aerobic dark) conditions in enriched MPYE (minerals, bactopeptone, and yeast extract) medium supplemented with antibiotics $(2.5 \mu \mathrm{g} / \mathrm{ml}$ Tet) and L-ara (0.5\%), as needed (30).

Construction of CcoA mutants. Standard molecular genetic techniques were performed as described previously (31). The plasmids and primer sequences used are listed in Tables $\mathrm{S} 1$ and $\mathrm{S} 2$, respectively. The plasmid pBK68 carrying the L-ara-inducible $c c o A$ is a derivative of pBAD/Myc-HisA (17) and used as a template for site-directed mutagenesis. Appropriate forward and reverse mutagenesis primers (see Table S2) were used to generate the plasmids pBK98 $\left(M_{30} A\right)$, pBK99 $\left(M_{32} A\right)$, pBK100 $\left(M_{69} A\right)$, pBK101 $\left(M_{73} A\right)$, pSP6 $\left(M_{227} A\right)$, pSP4 $\left(\mathrm{H}_{249} \mathrm{~A}\right)$, pSP5 $\left(\mathrm{H}_{274} \mathrm{~A}\right)$, pBK108 $\left(\mathrm{C}_{49} \mathrm{~A}\right)$, pBK109 $\left(\mathrm{C}_{109} \mathrm{~A}\right)$, pSP9 $\left(\mathrm{C}_{225} \mathrm{~A}\right)$, pSP8 $\left(\mathrm{C}_{247} \mathrm{~A}\right)$, and $\mathrm{pBK} 117\left(\mathrm{C}_{367} \mathrm{~A}\right)$, producing $\mathrm{Cco} A$ variants with the indicated mutations (see Table S1). These plasmids served as the templates for generating the $\operatorname{cco} A$ double Met or Cys mutants by using appropriate forward and reverse primers (see Table S2) to yield pBK79 $\left(M_{237} A+M_{265} A\right)$, pBK119 $\left(C_{49} A+C_{109} A\right)$, pBK122 $\left(C_{49} A+C_{247} A\right)$, pBK126 $\left(C_{109} A+C_{247} A\right)$, pBK123 $\left(C_{247} A+C_{367} A\right)$, and pBK129 $\left(C_{109} A+C_{367} A\right)$, producing mutant $C$ co $A$ variants (see Table $\left.S 1\right)$. The pBAD derivatives carrying the mutant alleles of $c c o A$ were cut with $\mathrm{Nsil}$ and ligated to the Pstl site of the broad-host-range plasmid pRK415 to generate the following pBAD-pRK415 composite plasmid derivatives carrying the mutant ccoA alleles: pBK90 $\left(\mathrm{H}_{249} \mathrm{~A}\right)$, pBK95 $\left(\mathrm{M}_{237} \mathrm{~A}+\mathrm{M}_{265} \mathrm{~A}\right)$, pBK102 $\left(\mathrm{M}_{30} \mathrm{~A}\right)$, pBK103 $\left(\mathrm{M}_{32} \mathrm{~A}\right)$, pBK104 (M69), pBK105 (M73A), pBK92 (M227 A), pBK91 ( $\left.\mathrm{H}_{249} A\right)$, pBK111 (C $\left.\mathrm{C}_{49} \mathrm{~A}\right)$, pBK112 $\left(\mathrm{C}_{109} \mathrm{~A}\right)$, pBK94 $\left(\mathrm{C}_{225} \mathrm{~A}\right)$, pBK93 $\left(\mathrm{C}_{247} \mathrm{~A}\right), \mathrm{pBK} 120\left(\mathrm{C}_{367} \mathrm{~A}\right), \mathrm{pBK} 121$ $\left(C_{49} A+C_{109} A\right), \quad p B K 124 \quad\left(C_{49} A+C_{247} A\right), \quad p B K 127 \quad\left(C_{109} A+C_{247} A\right), \quad p B K 125$ $\left(C_{247} A+C_{367} A\right)$, and pBK130 $\left(C_{109} A+C_{367} A\right)$ (see Table S1). These pRK derivatives were conjugated into appropriate $R$. capsulatus strains, as described earlier (17).

\section{Chromatophore membrane preparation, SDS-PAGE, and} immunodetection. Intracytoplasmic membrane vesicles (chromatophore membranes) were prepared in $20 \mathrm{mM}$ Tris- $\mathrm{HCl}(\mathrm{pH} 7.0)$ containing $150 \mathrm{mM} \mathrm{NaCl}$ and $1 \mathrm{mM}$ phenylmethylsulfonylfluoride (PMSF) as previously described (30). Total protein concentrations were determined using the bicinchoninic acid assay (Sigma, Inc., procedure TPRO-562), and SDS-PAGE (12\%) analyses were conducted as described previously (32). Prior to loading, 20 or $40 \mu \mathrm{g}$ of proteins samples of $E$. coli or $R$. capsulatus, respectively, were solubilized by incubation at 
room temperature for $10 \mathrm{~min}$ in a loading buffer (final concentration of $62.5 \mathrm{mM}$ Tris- $\mathrm{HCl}$ [pH 6.8], 2\% SDS, 2\% $\beta$-mercaptoethanol, and $0.01 \%$ bromophenol blue). After electrophoresis, gels were electroblotted onto Immobilon-P polyvinylidene difluoride membranes (Millipore, Inc.), and probed with anti c-Myc tag monoclonal antibodies (clone 9E10 from the University of Pennsylvania Cell Center). The secondary antibodies were horseradish peroxidase-conjugated antimouse IgGs (GE Healthcare, Inc.), and the signal was detected using Supersignal West Pico chemiluminescence substrate according to the supplier's recommendations (Thermo Fisher, Inc.).

Determination of the free thiol groups and disulfide bonds of CCOA in vivo. E. coli cells producing wild-type or appropriate Cys mutant derivatives of CcoA were analyzed by alkylating free Cys thiols with methoxy-polyethylene glycol-maleimide (mPEG-MAL) before and after DTT reduction, as previously described (22). Strains producing desired CcoA variants were grown overnight at $37^{\circ} \mathrm{C}$ in $5 \mathrm{ml}$ of LB medium supplemented with appropriate antibiotics (Amp, 100 $\mu \mathrm{g} / \mathrm{ml}$; Tet, $10 \mu \mathrm{g} / \mathrm{ml}$ ) with shaking at $180 \mathrm{rpm}$. The next day, 100 to $200 \mu \mathrm{l}$ of these cultures were subcultured into $10 \mathrm{ml}$ of fresh LB medium containing $1 \% \mathrm{~L}$-ara and appropriate antibiotics at $37^{\circ} \mathrm{C}$ with shaking $(180 \mathrm{rpm})$ until they reached an optical density at $600 \mathrm{~nm}\left(\mathrm{OD}_{600}\right)$ of 0.5 . At this stage, two aliquots of $0.9 \mathrm{ml}$ each were taken out and kept on ice, while the remaining culture $(8.2 \mathrm{ml})$ was reduced by addition of $82 \mu$ of $1.0 \mathrm{M}$ DTT (10 mM final concentration) and further incubated for $10 \mathrm{~min}$ at $37^{\circ} \mathrm{C}$ with shaking. Two additional aliquots of $0.9 \mathrm{ml}$ each were taken and placed on ice. All four samples were precipitated by addition of $100 \mu \mathrm{l}$ of $100 \%$ ice-cold TCA (final concentration, 10\% [vol/vol]) and incubated on ice for 30 min. Precipitated materials were centrifuged at $13,000 \mathrm{rpm}$ at $4^{\circ} \mathrm{C}$ for $12 \mathrm{~min}$, and supernatants were removed without disturbing the pellets, which were washed with $300 \mu \mathrm{l}$ of ice-cold acetone to eliminate TCA, and recentrifuged under the same conditions. The pellets were partially dried at $30^{\circ} \mathrm{C}$ for $\sim 10 \mathrm{~min}$ to evaporate acetone, one untreated pellet and one DTT-treated pellet were resuspended in 30 $\mu \mathrm{l}$ of PBS buffer (137 mM NaCl, $2.7 \mathrm{mM} \mathrm{KCl,} 10 \mathrm{mM} \mathrm{Na} 2 \mathrm{HPO}_{4}, 2.0 \mathrm{mM} \mathrm{KH}_{2} \mathrm{PO}_{4}$ [pH 7.0]) supplemented with $0.1 \%$ SDS. Similarly, the remaining one untreated and one DTT-treated pellets were resuspended in $30 \mu \mathrm{l}$ of mPEG-MAL solution (20 mM mPEG-MAL dissolved in PBS buffer) supplemented with $0.1 \%$ SDS. The pellets were vortexed vigorously for $1 \mathrm{~min}$ for complete dissolution, followed by incubation in the dark at room temperature for $2 \mathrm{~h}$ under constant shaking $(1,000$ rpm) to label the accessible thiol groups of CcoA. At the end of the incubation, 10 $\mu \mathrm{l}$ of $5 \times$ Laemmli buffer (10\% SDS [vol/vol], $0.05 \%$ bromophenol blue [wt/vol], $60 \%$ glycerol [vol/vol], $300 \mathrm{mM}$ Tris- $\mathrm{HCl}$ [pH 6.8]) was added to each sample, followed by further incubation at room temperature for $15 \mathrm{~min}$. Then, $20 \mu \mathrm{l}$ of each sample was loaded on a $12 \%$ nonreducing SDS-PAGE gel, run at $200 \mathrm{~V}$, and subjected to immunoblot analyses using a-myc monoclonal antibodies (1:5,000 dilution) as primary antibodies and horseradish peroxidase conjugated anti-mouse lgGs as secondary antibodies (1:3,000 dilution). The addition of MPEG-MAL, specific to free thiol groups, increases the $M_{r}$ of alkylated mPEG-MAL derivatives of CcoA, with the increases being proportional to the number of free thiol groups. Comparison of untreated and DTT-treated samples prior to MPEG-MAL alkylation visualized the DTT-reduced disulfide bonds of CcoA in vivo under the growth conditions used.

$c b b_{3}$-Cox activity. The in situ $c b b_{3}$-Cox activity of $R$. capsulatus colonies was 
assessed qualitatively using the "NADI" staining solution, which is made by mixing in a 1:1 (vol/vol) ratio $35 \mathrm{mM}$ a-naphthol and $30 \mathrm{mM} N, N, N^{\prime}, N^{\prime}$-dimethylp-phenylene diamine (DMPD) dissolved in ethanol and water, respectively (33). Colonies producing $c b b_{3}$-Cox stain blue, while those lacking it remain unstained. The in vitro $c b b_{3}-$ Cox activity was measured quantitatively using $R$. capsulatus chromatophore membranes and TMPD by monitoring spectrophotometrically in a stirred cuvette its oxidized form at $562 \mathrm{~nm}\left(\lambda_{562}=11.7\right)$ at room temperature. Briefly, $10 \mu \mathrm{g}$ of $R$. capsulatus chromatophore membranes was added to $1 \mathrm{ml}$ of assay buffer (25 mM Tris- $\mathrm{HCl}$ [pH 7.0], $150 \mathrm{mM} \mathrm{NaCl}$ ), and the enzymatic reaction was initiated by addition of TMPD at a final concentration of $1 \mathrm{mM}$. The TMPD oxidation specifically due to $c b b_{3}$-Cox activity was controlled by incubating the chromatophore membranes with $200 \mu \mathrm{M}$ KCN for 2 min prior to TMPD addition. The $c b b_{3}$-Cox activity was calculated by subtracting from the TMPD oxidase activity the fraction that was KCN insensitive (15).

Radioactive ${ }^{64} \mathrm{Cu}$ uptake assays. Cellular $\mathrm{Cu}$ uptake assays were performed as previously described (12), using whole cells and radioactive ${ }^{64} \mathrm{Cu}\left(1.84 \times 10^{4}\right.$ $\mathrm{mCi} / \mu \mathrm{mol}$ specific activity) obtained from Mallinckrodt Institute of Radiology, Washington University Medical School. The. E. coli strains harboring appropriate pBAD/Myc-His derivatives with L-ara-inducible ccoA wild- type and mutant variants (see Table S1) were grown overnight in $10 \mathrm{ml}$ of LB medium supplemented with $0.5 \%$ L-ara and appropriate antibiotics. Cells were pelleted, washed with the assay buffer (50 mM sodium citrate [pH 6.5], 5\% glucose), and resuspended in $1 \mathrm{ml}$ of the same buffer. All cultures were normalized to the same number of cells $(7.5 \times$ $10^{8}$ cells/500 $\mu$ l of assay volume) based on their absorbance $\left(1 \mathrm{OD}_{600}=5 \times 10^{8}\right.$ cells $/ \mathrm{ml}$ for $E$. coli and $1 \mathrm{OD}_{630}=7.5 \times 10^{8} \mathrm{cells} / \mathrm{ml}$ for $R$. capsulatus strains). Cells to be assayed for ${ }^{64} \mathrm{Cu}$ uptake were preincubated at 35 or $0^{\circ} \mathrm{C}$ for $10 \mathrm{~min}$ before the assay. The uptake activity was initiated by addition of $10^{7} \mathrm{cpm}$ of ${ }^{64} \mathrm{Cu}$, determined immediately before use (half-life of ${ }^{64} \mathrm{Cu}$ isotope $\sim 12 \mathrm{~h}$ ), and $50-\mu \mathrm{l}$ aliquots were taken at $0,1,2,5$, and $10 \mathrm{~min}$ of incubation and immediately mixed with ice-cold $50 \mu \mathrm{l}$ of $1 \mathrm{mM} \mathrm{CuCl} 2$ and $50 \mu \mathrm{l}$ of $50 \mathrm{mM}$ EDTA ( $\mathrm{pH} \mathrm{6.5)} \mathrm{to} \mathrm{stop} \mathrm{the}$ uptake reaction. All aliquots were kept on ice until the end of the assay; the cells were then pelleted, and the pellets were washed twice with $100 \mu \mathrm{l}$ of ice-cold 50 $\mathrm{mM}$ EDTA solution, resuspended in $1 \mathrm{ml}$ of scintillation liquid, and counted using a scintillation counter (Coulter-Beckman, Inc.) with a wide-open window. For each time point, the background ${ }^{64} \mathrm{Cu}$ uptake activity seen at $0^{\circ} \mathrm{C}$ was subtracted from that at $35^{\circ} \mathrm{C}$ and plotted as a function of time to compare CcoA-specific $\mathrm{Cu}$ uptake of wild-type control $(\triangle c c o A /$ plasmid-born $c c o A)$ and mutant derivatives of CcoA.

\section{NOTE}

This article is a direct contribution from Fevzi Daldal, a Fellow of the American Academy of Microbiology, who arranged for and secured reviews by J. Beatty, University of British Columbia; Soufian Ouchane, French National Centre for Scientific Research; and Carsten Sanders, Kutztown University of Pennsylvania.

\section{ACKNOWLEDGMENTS}

This study was supported mainly by the Division of Chemical Sciences, Geosciences and Biosciences, Office of Basic Energy Sciences of Department of Energy (DOE DEFG02-91ER20052) to F.D., partly by the National Institutes of Health (GM 38237) to F.D., and by the Deutsche Forschungsgemeinschaft (RTG 2202, Project-ID 278002225) to H.G.K.

We declare that the research was conducted in the absence of any commercial or 
financial relationships that could be construed as a potential conflict of interest.

All authors have given approval to the final version of the manuscript. B.K.-H., P.-I.T., and F.D. designed, performed experiments, and analyzed data. S.S. performed structural analyses, and all authors critically read and edited the manuscript. B.K.-H., H.-G.K., and F.D. supervised the study.

\section{REFERENCES}

1. Marger MD, Saier MH, Jr. 1993. A major superfamily of transmembrane facilitators that catalyse uniport, symport and antiport. Trends Biochem Sci 18:13-20. 10.1016/0968-0004(93)90081-W. PubMed.

2. Pao SS, Paulsen IT, Saier MH, Jr. 1998. Major facilitator superfamily. Microbiol Mol Biol Rev 62:1-34. 10.1128/MMBR.62.1.1-34.1998. PubMed.

3. Yan N. 2013. Structural advances for the major facilitator superfamily (MFS) transporters. Trends Biochem Sci 38:151-159. 10.1016/j.tibs.2013.01.003. PubMed.

4. Quistgaard EM, Low C, Guettou F, Nordlund P. 2016. Understanding transport by the major facilitator superfamily (MFS): structures pave the way. Nat Rev Mol Cell Biol 17:123-132. 10.1038/nrm.2015.25. PubMed.

5. Abramson J, Smirnova I, Kasho V, Verner G, Kaback HR, Iwata S. 2003. Structure and mechanism of the lactose permease of Escherichia coli. Science 301:610-615. 10.1126/science.1088196. PubMed.

6. Abramson J, Riistama S, Larsson G, Jasaitis A, Svensson-Ek M, Laakkonen L, Puustinen A, Iwata S, Wikstrom M. 2000. The structure of the ubiquinol oxidase from Escherichia coli and its ubiquinone binding site. Nat Struct Biol 7:910-917. 10.1038/82824. PubMed.

7. Abramson J, Smirnova I, Kasho V, Verner G, Iwata S, Kaback HR. 2003. The lactose permease of Escherichia coli: overall structure, the sugar-binding site and the alternating access model for transport. FEBS Lett 555:96-101. 10.1016/s0014-5793(03)01087-1. PubMed.

8. Zhou Y, Jiang X, Kaback HR. 2012. Role of the irreplaceable residues in the LacY alternating access mechanism. Proc Natl Acad Sci U S A 109:12438-12442. 10.1073/pnas.1210684109. PubMed.

9. Solcan N, Kwok J, Fowler PW, Cameron AD, Drew D, Iwata S, Newstead S. 2012. Alternating access mechanism in the POT family of oligopeptide transporters. EMBO J 31:3411-3421. 10.1038/emboj.2012.157. PubMed.

10. Ekici S, Yang H, Koch HG, Daldal F. 2012. Novel transporter required for biogenesis of cbb3-type cytochrome $c$ oxidase in Rhodobacter capsulatus. mBio 3:e00293-11. 10.1128/mBio.00293-11. PubMed.

11. Beaudoin J, Ekici S, Daldal F, Ait-Mohand S, Guerin B, Labbe S. 2013. Copper transport and regulation in Schizosaccharomyces pombe. Biochem Soc Trans 41:1679-1686. 10.1042/BST2013089. PubMed.

12. Ekici S, Turkarslan S, Pawlik G, Dancis A, Baliga NS, Koch HG, Daldal F. 2014. Intracytoplasmic copper homeostasis controls cytochrome $c$ oxidase production. mBio 5:e01055-13. 10.1128/mBio.01055-13. PubMed.

13. Zhang Y, Blaby-Haas CE, Steimle S, Verissimo AF, Garcia-Angulo VA, Koch HG, Daldal F, Khalfaoui-Hassani B. 2019. Cu transport by the extended family of CcoA-like transporters (CalT) in proteobacteria. Sci Rep 9:1208. 10.1038/s41598-018-37988-4. PubMed.

14. Ekici S, Pawlik G, Lohmeyer E, Koch HG, Daldal F. 2012. Biogenesis of cbb3-type cytochrome $c$ oxidase in Rhodobacter capsulatus. Biochim Biophys Acta 1817:898-910. 10.1016/j.bbabio.2011.10.011. PubMed. 
15. Khalfaoui-Hassani B, Wu H, Blaby-Haas CE, Zhang Y, Sandri F, Verissimo AF, Koch HG, Daldal F. 2018. Widespread distribution and functional specificity of the copper importer $\mathrm{CcoA}$ : distinct $\mathrm{Cu}$ uptake routes for bacterial cytochrome $\mathrm{c}$ oxidases. mBio 9:e00065-18. 10.1128/mBio.00065-18. PubMed.

16. Khalfaoui-Hassani B, Verissimo AF, Shroff NP, Ekici S, Trasnea P-I, Utz M, Koch HG, Daldal F. 2016. Biogenesis of cytochrome $c$ complexes: from insertion of redox cofactors to assembly of different subunits, p 527-554. In Cramer WA, Kallas T (ed), Cytochrome complexes: evolution, structures, energy transduction and signaling. Springer, Dordrecht, the Netherlands.

17. Khalfaoui-Hassani B, Verissimo AF, Koch HG, Daldal F. 2016. Uncovering the transmembrane metal binding site of the novel bacterial major facilitator superfamilytype copper importer CcoA. mBio 7:e01981-15. 10.1128/mBio.01981-15. PubMed.

18. Dancis A, Yuan DS, Haile D, Askwith C, Eide D, Moehle C, Kaplan J, Klausner RD. 1994. Molecular characterization of a copper transport protein in Saccharomyces cerevisiae: an unexpected role for copper in iron transport. Cell 76:393-402. 10.1016/0092-8674(94)90345-X. PubMed.

19. Arguello JM, Patel SJ, Quintana J. 2016. Bacterial $\mathrm{Cu}^{+}$-ATPases: models for molecular structure-function studies. Metallomics 8:906-914. 10.1039/c6mt00089d. PubMed.

20. Jiang J, Nadas IA, Kim MA, Franz KJ. 2005. A Mets motif peptide found in copper transport proteins selectively binds $\mathrm{Cu}(\mathrm{I})$ with methionine-only coordination. Inorg Chem 44:9787-9794. 10.1021/ic051180m. PubMed.

21. Taniguchi R, Kato HE, Font J, Deshpande CN, Wada M, Ito K, Ishitani R, Jormakka M, Nureki O. 2015. Outward- and inward-facing structures of a putative bacterial transitionmetal transporter with homology to ferroportin. Nat Commun 6:8545. 10.1038/ncomms9545. PubMed.

22. Ke N, Berkmen M. 2014. Production of disulfide-bonded proteins in Escherichia coli. Curr Protoc Mol Biol 108:16.1B.1-21. 10.1002/0471142727.mb1601bs108. PubMed.

23. Verissimo AF, Khalfaoui-Hassani B, Hwang J, Steimle S, Selamoglu N, Sanders C, Khatchikian CE, Daldal F. 2017. The thioreduction component CcmG confers efficiency and the heme ligation component $\mathrm{CcmH}$ ensures stereo-specificity during cytochrome $c$ maturation. J Biol Chem 292:13154-13167. 10.1074/jbc.M117.794586. PubMed.

24. Onder O, Verissimo AF, Khalfaoui-Hassani B, Peters A, Koch HG, Daldal F. 2017. Absence of thiol-disulfide oxidoreductase DsbA impairs $c b b_{3}$-type cytochrome $c$ oxidase biogenesis in Rhodobacter capsulatus. Front Microbiol 8:2576. 10.3389/fmicb.2017.02576. PubMed.

25. De Feo CJ, Aller SG, Siluvai GS, Blackburn NJ, Unger VM. 2009. Three-dimensional structure of the human copper transporter hCTR1. Proc Natl Acad Sci U S A 106:4237-4242. 10.1073/pnas.0810286106. PubMed.

26. Puig S, Lee J, Lau M, Thiele DJ. 2002. Biochemical and genetic analyses of yeast and human high affinity copper transporters suggest a conserved mechanism for copper uptake. J Biol Chem 277:26021-26030. 10.1074/jbc.M202547200. PubMed.

27. Ren F, Logeman BL, Zhang X, Liu Y, Thiele DJ, Yuan P. 2019. X-ray structures of the high-affinity copper transporter Ctr1. Nat Commun 10:1386. 10.1038/s41467-019-09376-7. PubMed.

28. Long F, Su CC, Lei HT, Bolla JR, Do SV, Yu EW. 2012. Structure and mechanism of the tripartite CusCBA heavy-metal efflux complex. Philos Trans $R$ Soc Lond B Biol Sci 367:1047-1058. 10.1098/rstb.2011.0203. PubMed.

29. Delmar JA, Su CC, Yu EW. 2015. Heavy metal transport by the CusCFBA efflux system. Protein Sci 24:1720-1736. 10.1002/pro.2764. PubMed. 
30. Darrouzet E, Valkova-Valchanova M, Daldal F. 2002. The [2Fe-2S] cluster $E(m)$ as an indicator of the iron-sulfur subunit position in the ubihydroquinone oxidation site of the cytochrome bc1 complex. J Biol Chem 277:3464-3470. 10.1074/jbc.M107973200. PubMed.

31. Sambrook J, Russell DW. 2001. Molecular cloning: a laboratory manual, 3rd ed. Cold Spring Harbor Laboratory Press, Cold Spring Harbor, NY.

32. Laemmli UK. 1970. Cleavage of structural proteins during the assembly of the head of bacteriophage T4. Nature 227:680-685. 10.1038/227680a0. PubMed.

33. Koch HG, Winterstein C, Saribas AS, Alben JO, Daldal F. 2000. Roles of the ccoGHIS gene products in the biogenesis of the $c_{b} b_{3}$-type cytochrome $c$ oxidase. $\mathrm{J} \mathrm{Mol} \mathrm{Biol}$ 297:49-65. 10.1006/jmbi.2000.3555. PubMed. 